\title{
LA POLÍTICA AMBIENTAL DE LA AUTORIDAD INTERNACIONAL DE LOS FONDOS MARINOS: EL EQUILIBRIO ENTRE LA EXPLOTACIÓN Y LA CONSERVACIÓN DEL PATRIMONIO COMÚN DE LA HUMANIDAD
}

\section{ENVIRONMENTAL POLICY OF THE INTERNATIONAL SEABED AUTHORITY: THE BALANCE BETWEEN THE EXPLOITATION AND CONSERVATION OF THE COMMON HERITAGE OF MANKIND}

\author{
M. Esther Salamanca Aguado* \\ Universidad de Valladolid \\ mariaesther.salamanca@uva.es
}

Fecha de recepción: 17 de octubre de 2019 / Fecha de aceptación: 2 de diciembre de 2019

\section{RESUMEN:}

Desde la entrada en vigor de la Convención de las Naciones Unidas sobre el Derecho del Mar y el Acuerdo relativo a la aplicación de su Parte XI, el 16 de noviembre de 1994, la Autoridad Internacional de los Fondos Marinos se ha ocupado principalmente de la aprobación de los reglamentos para la prospección y exploración de los minerales de la Zona internacional de los fondos marinos — "Código de minería" - y de la concesión de licencias de exploración. Se aproxima el momento en el que den comienzo las primeras actividades de explotación y la incertidumbre en cuanto a su posible impacto ambiental está centrando las negociaciones del nuevo reglamento sobre la explotación de minerales. En este estudio se abordan los principales desafíos que el diseño de la política ambiental de la Autoridad plantea con el fin de

\footnotetext{
* Profesora Contratado Doctor de Derecho Internacional Público y Relaciones Internacionales de la Universidad de Valladolid (Campus María Zambrano), e-mail: mariaesther.salamanca@uva.es. Miembro de la delegación española ante la Autoridad Internacional de los Fondos Marinos desde 2018. Las opiniones expresadas en este estudio son exclusivamente de la autora, no pudiendo ser consideradas opiniones oficiales del Gobierno de España.
} 
garantizar la protección eficaz del medio marino y la explotación sostenible de los recursos de la Zona, considerados patrimonio común de la humanidad.

\section{RESUM:}

Des de l'entrada en vigor de la Convenció de les Nacions Unides sobre el Dret del Mar i Acord relatiu a l'aplicació del seu Part XI, el 16 de novembre de 1994, l'Autoritat Internacional dels Fons Marins s'ha ocupat principalment de l'aprovació de les regulacions per a la prospecció i exploració dels minerals de la Zona internacional dels fons marins " - "Codi de mineria" — i de la concessió de licències d'exploració. Aproximadament el moment en què es comença a iniciar les primeres activitats d'explotació i l'incertesa en un possible impacte ambiental està centrant les negociacions del nou reglament sobre l'explotació de minerals. En aquest estudi s'aborden els principals desafiaments que el disseny de la política ambiental de l'autoritat planten amb l'objectiu de garantir la protecció eficaç del mitjà marí i l'explotació sostenible dels recursos de la Zona, considerats patrimoni comú de la humanitat.

\section{ABSTRACT:}

Since the entry into force of the United Nations Convention on the Law of the Sea and the Agreement concerning the application of its Part XI, on November 16, 1994, the International Seabed Authority has been primarily concerned with the approval of regulations for the exploration of minerals from the International Seabed Area — "Mining Code" — and the granting of exploration licenses. The time is approaching when the first exploitation activities begin and uncertainty regarding their possible environmental impact is focusing the negotiations of the new regulation on the exploitation of minerals. This study addresses the main challenges that the design of the Authority's environmental policy poses in order to guarantee the effective protection of the marine environment and the sustainable exploitation of the resources of the Area, considered a common heritage of mankind. 
PALABRAS CLAVE: Patrimonio común de la humanidad - Autoridad internacional de los fondos marinos - Minería oceánica - Criterio de precaución - Responsabilidad por daños - Planes regionales de gestión ambiental — Desarrollo Sostenible — Biodiversidad

PARAULES CLAU: Patrimoni comú de la humanitat - Autoritat internacional dels fons marins - Mineria oceánica - Criteri de precaució - Responsabilitat per danys - Plans regionals de gestió ambiental - Desenvolupament sostenible - Biodiversitat

KEYWORDS: Common Heritage of Mankind - International Seabed Authority - Ocean mining - Precautionary criteria - Liability for damages - Regional environmental management plans - Sustainable development — Biodiversity

SUMARIO: I. Introducción. II. La Autoridad internacional de los fondos marinos y la administración del patrimonio común de la humanidad. 1. El patrimonio común de la humanidad: la Zona y sus recursos. 2. La Autoridad: facultades y funciones. a) Organización y reglamentación. b) Control y supervisión de las actividades en la Zona. c) Promoción de la investigación científica marina y la transferencia de tecnología. 3. Etapa inicial: la exploración de los minerales de la Zona. a) El sistema paralelo y los arreglos de empresas conjuntas. b) Las actividades de prospección y exploración. III. La protección del medio marino contra los efectos derivados de las actividades en la Zona. 1. Marco jurídico. 2. Principios ambientales aplicados a las actividades en la Zona. a) Principio de utilización sostenible de los recursos. b) Principio de prevención del daño ambiental. c) Principio de precaución y mejores prácticas ambientales. d) Principio de cooperación: zonas de referencia para los efectos y zonas de referencia para la preservación. e) Principio de reparación del daño ambiental. f) Principio de transparencia. 3. Los planes regionales de gestión ambiental: requisito para el inicio de las actividades de explotación de los minerales de la Zona. a) Naturaleza jurídica y principios rectores. b) El plan regional de gestión ambiental para la zona de fractura Clarion - Clipperton. IV. Conclusiones.

\section{INTRODUCCIÓN}


En los últimos años los grupos ecologistas han dado la voz de alarma sobre los efectos irreversibles de la minería oceánica en aguas profundas. Parece como si la idea ilusionante de declarar los fondos marinos y oceánicos más allá de la jurisdicción nacional patrimonio común en los años 60 y 70, con la finalidad de explotar sus recursos en beneficio de toda la humanidad ${ }^{2}$, se haya tornado en la gran amenaza ambiental del siglo XXI. Paradójicamente, la organización internacional creada para administrar ese patrimonio común en nombre de la humanidad está siendo acusada, nada más y nada menos, de contribuir a su destrucción. Hay quienes consideran que la minería oceánica es incompatible con los Objetivos de Desarrollo Sostenible (ODS) ${ }^{3}$ y que es necesario abrir un debate sobre si existe o no la necesidad de iniciar la explotación de los minerales del fondo oceánico de cara a la transición energética ${ }^{4}$. Este debate está teniendo lugar al mismo tiempo que se negocia el nuevo acuerdo de aplicación de la Convención de Naciones Unidas sobre el Derecho del Mar (la Convención ) para la protección de la biodiversidad más allá de la jurisdicción nacional — el llamado proceso BBNJ 5 -

Greenpeace internacional publicó un informe en julio de 2019 en el que se alertaba sobre el daño irreversible de la minería oceánica sobre frágiles

\footnotetext{
2 En 17 de diciembre de 1970 la Asamblea General de las Naciones Unidas declaró solemnemente que "los fondos marinos y oceánicos y su subsuelo fuera de los límites de los límites de la jurisdicción nacional así como sus recursos son patrimonio común de la humanidad" [Resolución 2749 (XXV)]. Este principió fue positivado en el artículo 136 de la Convención de las Naciones Unidas sobre el Derecho del Mar de 1982 (BOE, núm. 39, de 14 de febrero de 1997, pp. 4966 a 5055) y desarrollado en cuanto al régimen jurídico de explotación y mecanismo institucional por la Parte XI de la misma y el Acuerdo de 1994 relativo a su aplicación (BOE, núm. 38, de 13 de febrero de 1997, pp. 4831 a 4849).

${ }^{3}$ En concreto el Objetivo 14: Conservar y utilizar en forma sostenible los océanos, los mares y los recursos marinos para el desarrollo sostenible. Véase la información publicada por Seas at Risk, una organización "paraguas" que agrupa ONGS ecologistas $(<$ https://seas-atrisk.org/issues/deep-sea-mining.html $>$ ) ([Última visita: 15 de octubre de 2019]) y por Deep Sea Conservation Coalition (DSCC) (<http://www.savethehighseas.org/deep-sea-mining/ $>$ ) ([Última visita: 15 de octubre de 2019]).

${ }^{4}$ Véase la intervención de Gerard Barron, CEO \& Chairman of DeepGreen Metals y miembro de la delegación de Nauru defendiendo la necesidad de iniciar la explotación de los minerales de la Zona y la respuesta de Deep Sea Conservation Coalition señalando que "deep sea mining at scale may not compensate for the potential marine biodiversity degradation, urging the Council not to confuse economic viability with social necessity", 27.02.2019, durante la primera parte del 25 período de sesiones del Consejo, ENB-IISD, Vol. 25 No. 183 (<http://enb.iisd.org/oceans/isa/2019-1/27feb.html>) ([Última visita: 15 de octubre de 2019]).

${ }^{5}$ Véase la información disponible en $<$ https://www.un.org/bbnj/ $>$ [Última visita: 15 de octubre de 2019]. Sobre las negociaciones véase E. M. Vázquez Gómez, "La protección de la biodiversidad biológica más allá de la jurisdicción nacional. Hacia un nuevo acuerdo de aplicación de la Convención de Naciones Unidas sobre el Derecho del Mar", R.E.E.I., Número 37, junio 2019.
} 
ecosistemas marinos aún desconocidos y se explicaba cómo podría empeorar la crisis climática al interrumpir las reservas de carbono azul en los sedimentos del fondo marino. También denunciaba que la Autoridad Internacional de Fondos Marinos (la Autoridad) no es apta para el propósito de proteger los océanos, estando más preocupada por promover los intereses de la industria minera que por defender la conservación del medio marino ${ }^{6}$.

A nivel europeo, la minería oceánica es un sector estratégico en el contexto del denominado crecimiento azul — Blue growth ${ }^{7}$ - Según varios informes durante el período comprendido entre los años 2000 y 2010, el precio de las materias primas no energéticas se incrementó en un $15 \%$ como resultado principalmente de la mayor demanda de los consumidores en las economías emergentes. Por lo que se ha determinado que en el caso de varias de esas materias, incluidas las reconocidas como fundamentales para la economía europea, existe un riesgo de insuficiencia de suministros. Se prevé que antes de que finalice 2020 , el $5 \%$ de los minerales utilizados en el mundo incluidos el cobalto, el cobre y el zinc - proceda ya del lecho de los océanos y que, para el 2030, esa proporción llegue al 10\%. Se estima que el volumen de negocios anual de la industria minera marítima pase de prácticamente cero a 5.000 millones de euros en los próximos diez años y que alcance los 10.000 millones antes de que termine 2030. Por el momento, las actividades de extracción se localizan en zonas bajo jurisdicción nacional — plataformas continentales - aunque se pretende que la industria europea llegue a ser competitiva en este nuevo sector, garantizando al mismo tiempo que esta actividad no impida a las generaciones futuras beneficiarse de ecosistemas que hasta ahora se habían mantenido vírgenes ${ }^{8}$.

\footnotetext{
${ }^{6}$ Greenpeace, In Deep Water. The emerging threat of deep sea mining, 3 de Julio de 2019, $<$ https://www.greenpeace.org/international/publication/22578/deep-sea-mining-in-deep-water/> [Última visita: 15 de octubre de 2019].

7 Comisión Europea, Comunicación de la Comisión al Parlamento Europeo, al Consejo, al Comité Económico y Social Europeo y al Comité de las Regiones. Crecimiento azul. Oportunidades para un crecimiento marino y marítimo sostenible, COM (2012) 494 final, Bruselas, 13.9.2012, punto. 5.4.

8 Ibíd., p. 15. Véanse los proyectos financiados por la Unión Europea BlueMining $<$ https://bluemining.eu/project/> y Seabed Mineral Deposits in European Seas: Metallogeny and Geological Potential for Strategic and Critical Raw Materials (MINDeSEA) $<$ https://geoera.eu/projects/mindesea2/> [Última visita: 15 de octubre de 2019].
} 
Haciéndose eco de las peticiones de los grupos ecologistas, el Parlamento Europeo ha instado a la Comisión a que pida a los Estados miembros que dejen de patrocinar las autorizaciones de prospección y exploración de los fondos marinos en las zonas fuera de su jurisdicción nacional y que no expidan autorizaciones para la minería de los fondos marinos en su plataforma continental. Igualmente, ha pedido a la Comisión y a los Estados miembros que apoyen una moratoria internacional sobre las licencias comerciales de explotación minera de los fondos marinos hasta que se hayan estudiado e investigado lo suficiente los efectos de la minería sobre el medio marino, la biodiversidad y las actividades humanas en el mar, y se hayan entendido todos los posibles riesgos ${ }^{9}$. Por su parte, el sector pesquero, a través del Consejo Consultivo de Flota de Larga Distancia en Aguas no Comunitarias (LDAC) ha apoyado el llamamiento a esta moratoria ${ }^{10}$.

En este sentido, conviene recordar que la Convención persigue el equilibrio entre los intereses del desarrollo y las inquietudes ambientales. Esto significa que la necesaria protección del medio marino no puede o no debe impedir, cuando llegue el momento, el desarrollo de este nuevo sector industrial. Este delicado equilibrio entre explotación y conservación fue puesto de manifiesto por la Sala de Controversias de los Fondos Marinos (la Sala) en su opinión consultiva de 2011 al destacar la necesidad de salvaguardar el objetivo de aplicar de forma uniforme los más altos estándares de protección del medio marino, el desarrollo seguro de las actividades en la Zona y la protección del patrimonio común de la humanidad ${ }^{11}$. En los próximos apartados abordaremos los principales desafíos que el diseño de una política ambiental de la Autoridad plantea con el fin de garantizar la protección eficaz del medio marino y la explotación sostenible de los minerales de la Zona.

\footnotetext{
9 Resolución del Parlamento Europeo, de 16 de enero de 2018, sobre la gobernanza internacional de los océanos: una agenda para el futuro de nuestros océanos en el contexto de los Objetivos de Desarrollo Sostenible para 2030 (2017/2055(INI)).

10 Véase la nota publicada por el LDCA instando a la Comisión Europea y a los Estados miembros a prohibir la minería submarina en alta mar $<$ https://ldac.eu/images/Final NdP LDAC Miner\%C3\%ADa Submarina mayo2019.pdfs ([Última visita: 15 de octubre de 2019]).

11 ITLOS, Responsibilities and Obligations of States Sponsoring Persons and Entities with respect to Activities in the Area. Advisory Opinion of 1 February 2011 (List of cases: No. 17) párr. 15.
} 


\section{LA AUTORIDAD INTERNACIONAL DE LOS FONDOS MARINOS Y LA ADMINISTRACIÓN DEL PATRIMONIO COMÚN DE LA HUMANIDAD}

\section{El patrimonio común de la humanidad: la Zona y sus recursos}

La Zona internacional de los fondos marinos (la Zona) y sus recursos son patrimonio común de la humanidad $(\mathrm{PCH})^{12}$. La Convención declinó este principio en una serie de corolarios normativos: la no apropiación y exclusión de soberanía, el uso pacífico, el beneficio de toda la humanidad y el uso sostenible de los recursos ${ }^{13}$. En su dimensión institucional el $\mathrm{PCH}$ comporta que la Autoridad organiza, realiza y controla las actividades en la Zona en nombre de la humanidad, aunque a través de la acción de sus Estados miembros ${ }^{14}$. En el plano axiológico el PCH expresa el valor de la solidaridad internacional en su dimensión inter-espacial — entre las generaciones actuales — e inter-temporal — en relación con las generaciones futuras — ${ }^{15}$.

En la práctica, el PCH opera como un principio rector de las políticas de la Autoridad, en el sentido de que inspira y orienta el desarrollo y la aplicación de las disposiciones de la Parte $\mathrm{XI}$ y del Acuerdo, configurando un nuevo modelo de gestión de los recursos naturales en beneficio de la humanidad. Así se desprende del Plan estratégico de la Autoridad para el período 2019 - 2023 y de su Plan de Acción de Alto Nivel ${ }^{16}$. Frente a la denominada "tragedia de los comunes"17, el régimen jurídico del $\mathrm{PCH}$ ofrece la oportunidad de una

\footnotetext{
${ }^{12}$ Art. 136, Convención.

${ }^{13}$ Arts. $137,140,141,150$ (b) y 145 , Convención.

${ }^{14}$ Arts. 137 (2) y 153 (1), Convención; Secc. 1 (1), Anexo, Acuerdo.

${ }^{15}$ Para un análisis más detallado de las tres dimensiones del principio de patrimonio común de la humanidad véase E. Salamanca Aguado, La Zona internacional de los fondos marinos. Patrimonio común de la humanidad, Dykinson, 2003, pp. $301-321$.

${ }^{16}$ Decisión de la Asamblea de la Autoridad Internacional de los Fondos Marinos en relación con el plan estratégico de la Autoridad para el período 2019-2023, ISBA/24/A/10, 27 de julio de 2018, Anexo, párr. 4 (a). High Level Action Plan of the International Seabed Authority and priorities for the 2019-2023 period, 3 May 2019, Dirección estratégica 1.3.

${ }_{17}$ Esta expresión fue usada por Garret Hardi en un artículo publicado en la revista Science en 1968. El autor afirmaba que "[e]ach man is locked into a system that compels him to increase his herd without limit-in a world that is limited. Ruin is the destination toward which all men rush, each pursuing his own best interest in a society that believes in the freedom of the commons. Freedom in a commons brings ruin to all". G. Hardi, "The Tragedy of the Commons", Science, vol. 162, p. 1244.
} 
administración coordinada e institucionalizada a nivel mundial ${ }^{18}$. Este aspecto es especialmente relevante en la materia que nos ocupa: la política ambiental de la Autoridad. Otro ámbito en el que el principio de $\mathrm{PCH}$ debe desplegar todos sus efectos, y del que no nos podemos ocupar en este estudio, es en el diseño del modelo económico que servirá de base a las disposiciones financieras de los contratos $^{19}$.

La Parte XI y el Acuerdo se aplican exclusivamente a la Zona, es decir, a los fondos marinos y oceánicos y su subsuelo fuera de los límites de la jurisdicción nacional ${ }^{20}$. Es decir, la Zona coincide con los límites geográficos del PCH y constituye el ámbito territorial de la competencia de la Autoridad. Sin embargo, sería erróneo afirmar que la Zona, como tal, se encuentra administrada por la Autoridad en su totalidad; muchos usos de la Zona, tales como el tendido de cables y tuberías submarinos y la investigación científica marina, pueden realizarse libremente sin su autorización y control. También quedan excluidos, fuera de su competencia, las aguas suprayacentes y el espacio aéreo situado sobre ellas ${ }^{21}$.

En la práctica, la Zona está aún sin delimitar, puesto que depende de los límites de la plataforma continental de los Estados ribereños. Según la Convención el Estado ribereño puede extender su plataforma continental hasta las 200 millas marinas — haya o no plataforma geológica — en cuyo caso sólo deberá depositar cartas e información pertinente en poder de los Secretarios Generales de las Naciones Unidas y de la Autoridad ${ }^{22}$. Por el contrario, el

\footnotetext{
18 En el derecho internacional contemporáneo se utilizan tres nociones para referirse a espacios o realidades que requieren una acción colectiva: (a) "espacios comunes" (common areas, "preocupación común" (common concern) y "patrimonio común". Esta última noción surge en los años 60 y 70 frente a la "tragedia de los comunes" para asegurar un reparto equitativo de los beneficios derivados de la explotación de los recursos. Sobre el tema véase J. Brunnée, "Common Areas, Common Heritage and Common Concern", en D. Bodansky (et al), The Oxford Handbook of International Environmental Law, Oxford University Press, 2010, pp. 550 - 573. Sobre la noción "preocupación común de la humanidad" en el actual contexto del proceso

BBNJ

véase $<$ https://www.un.org/depts/los/biodiversity/prepcom files/BowlingPiersonandRatte Common C oncern.pdf> [Última visita: 29 de noviembre de 2019].

${ }_{19}$ Véanse los informes presentados por el Massachusetts Institute of Technology (MIT) al "Grupo de trabajo de composición abierta del Consejo respecto de la elaboración y negociación de las disposiciones financieras de los contratos" disponibles en la web de la Autoridad $<$ https://www.isa.org.jm/sessions/25th-session-2019> [Última visita: 15 de octubre de 2019].

${ }^{20}$ Arts. 134 (1), Convención.

${ }^{21}$ Arts. 112, 146, 256 y 135, Convención.

${ }^{22}$ Arts. 76 (4) (9) y 84 (2), Convención.
} 
Estado ribereño no puede establecer de forma obligatoria, es decir, oponible a terceros Estados, el límite exterior de su plataforma continental más allá de las 200 millas marinas sin tomar como base las recomendaciones de la Comisión de Límites de la Plataforma Continental (CLPC) ${ }^{23}$. La Autoridad no tiene derecho a participar en el proceso de determinación del límite exterior de la plataforma continental, aunque se trate de los límites de los fondos marinos sobre los que la Autoridad ejerce su competencia. Los Estados ribereños sólo están obligados a dar publicidad de las cartas y listas coordenadas geográficas y depositar una copia en poder de los Secretarios Generales como se ha indicado anteriormente ${ }^{24}$.

Los recursos de la Zona definidos como $\mathrm{PCH}$ son todos los recursos minerales sólidos, líquidos o gaseosos in situ en la Zona, situados en los fondos marinos o en su subsuelo, incluidos los nódulos polimetálicos. Estos recursos son inalienables. No obstante, los minerales extraídos de la Zona podrán ser enajenados con arreglo a la Parte XI y a las normas, reglamentos y procedimientos de la Autoridad. Es decir, ningún Estado o persona natural o jurídica puede reivindicar, adquirir o ejercer derechos respecto de los minerales extraídos de la Zona, salvo de conformidad con la Parte XI. De otro modo, no se reconocerá tal reivindicación, adquisición o ejercicio de derechos ${ }^{25}$.

Hasta el momento, los recursos minerales que tienen importancia económica son, además de los nódulos polimetálicos, los sulfuros polimetálicos y las costras de ferromanganeso con alto contenido de cobalto ${ }^{26}$. También se han identificado depósitos de hidratos de metano aunque aún no se ha descubierto un método económico e inocuo de recuperación comercial del gas de los

\footnotetext{
${ }^{23}$ Arts. 76 (8) (9) y 84 (2), Convención.

${ }^{24}$ El Secretario General de la Autoridad recuerda cada año a los Estados miembros esta obligación. En su último informe vuelve a repetir que "a 31 de mayo de 2018, diez miembros de la Autoridad habían depositado esas cartas y listas en poder del Secretario General, a saber: Australia, Bahréin, Filipinas, Francia (con respecto a Martinica, Guadalupe, Guyana, Nueva Caledonia y las islas Kerguelen), Irlanda, Mauricio, México, Niue, Pakistán y Tuvalu". Es evidente, que hasta que la CLPC no finalice sus trabajos, la Zona estará sin delimitar, ISBA/25/A/2, 3 de mayo de 2019, para. 6 .

${ }^{25}$ Arts. 133 y 137 (2) (3), Convención.

${ }^{26}$ La Autoridad dispone de un Depósito Central de Datos (DCD) que contiene datos centralizados de información pública y privada sobre recursos minerales marinos adquirida de varios institutos del mundo. La Autoridad utiliza estos datos para estandarizar y evaluar datos de valoración cuantitativa de minerales <https://www.isa.org.jm/es/fondo-de-datos> [Última visita: 15 de octubre de 2019].
} 
hidratos, teniendo en cuenta que se trata de un gas de efecto invernadero, por lo que su exploración no ha sido regulada por la Autoridad.

Sin embargo, los avances en la biotecnología han puesto de manifiesto el potencial económico de otros recursos no incluidos en la definición de la Parte $\mathrm{XI}$ y, por tanto, excluidos del régimen jurídico del $\mathrm{PCH}$. Se trata de los recursos genéticos situados fuera de la jurisdicción nacional, cuya naturaleza jurídica y régimen de acceso está siendo objeto de discusión en el marco del proceso de negociación del futuro acuerdo de aplicación $\mathrm{BBNJ}^{27}$.

\section{La Autoridad: facultades y funciones}

La Autoridad tiene las facultades y funciones que expresamente se le confieren por la Convención y aquellas facultades accesorias, compatibles con la Convención, que resulten implícitas y necesarias para el ejercicio de aquellas facultades y funciones con respecto a las actividades en la Zona ${ }^{28}$. La Convención atribuye expresamente a la Autoridad tres tipos de funciones: la organización, la realización y el control de las actividades en la Zona ${ }^{29}$. Sin embargo, después de la enmienda introducida por el Acuerdo, en la etapa inicial — entre la entrada en vigor de la Convención y la aprobación del primer plan de trabajo para la explotación - la Autoridad ejerce principalmente funciones de organización, reglamentación y control de las actividades de exploración de los minerales de la Zona.

\section{a) Organización y reglamentación}

Las actividades en la Zona son organizadas por la Autoridad a través del establecimiento de políticas sobre cualquier cuestión 0 asunto de su competencia $^{30}$. La Asamblea, en colaboración con el Consejo, determina la

\footnotetext{
27 Sobre la cuestión de la naturaleza jurídica de los recursos genéticos de la Zona véase, E. Salamanca Aguado, "El régimen jurídico aplicable a la bioprospección de los recursos genéticos de los fondos oceánicos fuera de los límites de la jurisdicción nacional", R.E.D.I., vol. LVIII (2006), 2, pp. 1072 - 1078.

${ }^{28}$ Secc. 1 (1) Anexo, Acuerdo.

${ }^{29}$ Arts. 153 (1) y 157 (1), Convención y Secc. 1 (1) Anexo, Acuerdo.

${ }^{30}$ Arts. 160 (1) y 162 (1), Convención.
} 
política general de la Autoridad $^{31}$. Se trata de una competencia compartida entre la Asamblea y el Consejo ${ }^{32}$. La Parte XI y el Acuerdo contienen los principios y normas que sirven de base al establecimiento de esas políticas, especialmente el principio de $\mathrm{PCH}$. En particular, la Autoridad está facultada para aprobar normas, reglamentos y procedimientos para el desarrollo de las disposiciones más generales ${ }^{33}$. De nuevo nos encontramos ante una competencia compartida entre la Asamblea y el Consejo ${ }^{34}$.

El Acuerdo especifica que durante la etapa inicial la Autoridad se ocupará de la aprobación de las normas, reglamentos y procedimientos necesarios para la realización de las actividades en la Zona de forma progresiva, a medida que estas avancen ${ }^{35}$. En sus veinticinco años de funcionamiento la Autoridad ha aprobado tres reglamentos sobre prospección y exploración de nódulos polimetálicos, sulfuros polimetálicos y costras de ferromanganeso con alto contenido de cobalto ${ }^{36}$. Por su parte, la Comisión Jurídica y Técnica (CJT) ha aprobado recomendaciones sobre cuestiones técnicas y administrativas formuladas para la aplicación de las normas, reglamentos y procedimientos ${ }^{37}$.

\footnotetext{
31 Secc. 3 (1) Anexo, Acuerdo.

32 La Asamblea está integrada por todos los miembros de la Autoridad y adopta sus decisiones sobre cuestiones de fondo por consenso. Si éste no fuera posible, las decisiones serán adoptadas por mayoría de dos tercios de los miembros presentes y votantes [Secc. 3 (2) (3) y art. 159.8]. El Consejo está integrado por 36 miembros de la Autoridad distribuidos en cámaras: a) cuatro miembros escogidos entre los mayores consumidores o importadores de los productos básicos derivados de los minerales extraídos de la Zona, entre ellos los dos países con mayor producto interior bruto en el momento de entrada en vigor de la Convención; b) cuatro miembros escogidos entre los mayores inversionistas de actividades en la Zona; c) cuatro miembros escogido entre los mayores exportadores de minerales extraídos de la Zona; d) seis miembros escogidos entre los países en desarrollo que representen intereses especiales; e) dieciocho miembros escogidos de conformidad con el principio de asegurar una distribución geográfica equitativa. España es miembro del Consejo en esta última cámara. Las decisiones sobre cuestiones de fondo en el Consejo de adoptan por consenso y si éste no se alcanza por mayoría de dos tercios de los miembros presentes y votantes, a menos que se opongan a tales decisiones la mayoría en cualquiera de las cámaras [Secc. 3 (5) (15)], Anexo, Acuerdo.

${ }^{33}$ Secc. (5) (f), Anexo, Acuerdo; art. 17, Anexo III, Convención.

${ }^{34}$ Arts. 160 (2) (f) y 162 (2) (o), Convención.

${ }^{35}$ Secc. 1 (5) (f) Anexo, Acuerdo.

${ }^{36}$ Reglamento sobre Prospección y Exploración de Nódulos Polimetálicos en la Zona (aprobado el 13 de julio de 2000 y modificado el 25 de julio de 2013 y el 24 de julio de 2014 (ISBA/6/A/18; ISBA/19/A/9 e ISBA/A/12, ISBA/20/A/9). Reglamento sobre Prospección y Exploración de Sulfuros Polimetálicos en la Zona (aprobado el 7 de mayo de 2010 y modificado el 25 de julio de 2013 y el 24 de julio de 2014 (ISBA/16/A/12/Rev.1 e ISBA/19/A/12, ISBA/20/A/10). Reglamento sobre Prospección y Exploración de Costras de Ferromanganeso con Alto Contenido de Cobalto (ISBA/18/A/11 e ISBA/19/A/12).

${ }^{37}$ La última revisión es el documento Recomendaciones para la información de los contratistas con respecto a la evaluación de los posibles efectos ambientales de la exploración de
} 
Otro medio de que dispone la Autoridad para organizar las actividades en la Zona es la emisión de directrices a la Empresa sobre cómo serán desempeñadas las actividades en las áreas reservadas. Hay que destacar entre estas directrices aquélla por la cual la Empresa comenzará a funcionar de manera independiente ${ }^{38}$. Se trata de una competencia exclusiva del Consejo ${ }^{39}$.

La organización de las actividades en la Zona incluye también la adopción por parte del Consejo de decisiones tales como la aprobación o el rechazo de la recomendación de aprobación de un plan de trabajo formulada por la CJT; la aprobación de las prórrogas de los planes de trabajo; en caso de urgencia, la emisión de órdenes que podrán incluir la suspensión o el reajuste de las operaciones, a fin de impedir daños graves al medio marino; la exclusión de la explotación por contratistas o por la Empresa de ciertas áreas cuando pruebas fundadas indiquen que existe riesgo de causar daños graves al medio marino ${ }^{40}$. En el momento en que se inicie la producción comercial de los minerales extraídos de la Zona el Consejo, en base a una recomendación de la Comisión de Planificación Económica, se ocupará de la adopción de medidas necesarias y apropiadas para la protección de los Estados en desarrollo respecto de los efectos económicos adversos ${ }^{41}$. La Autoridad se ocupará también de la distribución equitativa de los beneficios financieros y otros beneficios económicos derivados de las actividades en la Zona mediante un mecanismo apropiado $^{42}$. Esta será una competencia compartida entre la Asamblea y el Consejo basándose en una recomendación del Comité de Finanzas ${ }^{43}$.

\section{b) Control y supervisión de las actividades en la Zona}

minerales marinos en la Zona (ISBA/19/LTC/8). Recomendaciones para la orientación de contratistas y Estados patrocinadores relativas a los programas de capacitación de conformidad con los planes de trabajo para la exploración (ISBA/19/LTC/14). Recomendaciones relativas a las orientaciones de los contratistas para la presentación de informes sobre los gastos de exploración efectivos y directos (ISBA/21/LTC/11). Recomendaciones para orientar a los contratistas respecto al contenido, el formato y la estructura de sus informes anuales (ISBA/21/LTC/15).

38 Secc. 2 (2), Anexo, Acuerdo.

39 Arts. 162 (2) (i) y 170, Convención.

40 Secc. 3 (11) (a) y Secc. 1 (9), Anexo, Acuerdo; Arts. 162. 2 (o), 162. 2 (x), Convención.

${ }^{41}$ Arts. 162. $2(\mathrm{~m})$, Convención.

42 Art. 140.2, Convención.

${ }^{43}$ Arts. 160.2 (f) (i) y 162 (o) (i), Convención; Secc. 3 (7) Anexo, Acuerdo. 
La Autoridad tiene la responsabilidad de controlar las actividades en la Zona. Si bien se trata de un control restringido, es decir, el control que sea necesario para lograr que se cumplan las disposiciones pertinentes de la Parte $\mathrm{XI}$, los anexos correspondientes, las normas, reglamentos y procedimientos y los planes de trabajo aprobados ${ }^{44}$. En virtud del artículo 153 (4) este control es ejercido por la Autoridad con la cooperación de los Estados Partes que están obligados a prestar asistencia a la Autoridad adoptando las medidas que sean necesarias para lograr dicho cumplimiento, de conformidad con el artículo 139. Esta disposición recoge la obligación de los Estados Partes de velar por que las actividades realizadas o patrocinadas por ellos se realicen de conforme a la Parte XI. A juicio de la Sala de Controversias la obligación de los Estados patrocinadores es directa, pero debe cumplirse mediante el cumplimiento de la obligación de diligencia debida establecida en el artículo $139^{45}$.

Por su parte, los solicitantes de un plan de trabajo se comprometen en sus solicitudes a aceptar el control de la Autoridad en la forma autorizada por la Convención y todo plan de trabajo aprobado preverá dicho control ${ }^{46}$. Por tanto, para controlar las actividades la Autoridad no necesita el consentimiento de los Estados o de los contratistas, la Convención le concede el derecho de adoptar en todo momento cualquiera de las medidas previstas para el desempeño de sus funciones de control y reglamentación. Por ejemplo, la Autoridad tiene derecho a inspeccionar todas las instalaciones utilizadas situadas en la Zona. Con este fin está previsto que el Consejo establezca un cuerpo de inspectores que examinen las actividades que se realizan y la CJT hará recomendaciones al Consejo sobre su dirección y supervisión y realizará ella misma funciones de supervisión e inspección ${ }^{47}$. También se prevé que la Autoridad adopte normas, reglamentos procedimientos relativos a la inspección y supervisión de las operaciones $^{48}$.

\footnotetext{
${ }^{44}$ Art. 153 (1), Convención.

${ }^{45}$ Advisory Opinion, párr. 124. En la opinión consultiva, la Sala señaló entre otras cosas que, con arreglo a la Convención, los Estados patrocinadores tienen la obligación de procurar que los contratistas patrocinados por ellos cumplan con las cláusulas del contrato y con las obligaciones establecidas en la Convención y los documentos conexos así como con las obligaciones directas que deben cumplir independientemente de su obligación de procurar que los contratistas patrocinados actúen en una forma determinada.

${ }^{46}$ Arts. 4. 6 (b), Anexo III, Convención.

${ }^{47}$ Arts. 153 (5), 162.2 (z) y 165 (3), Convención.

${ }^{48}$ Art. 17.1 (b) (viii), Anexo III, Convención.
} 
La Autoridad cuenta además con la facultad de suspender o rescindir el contrato si la forma en que el contratista ha realizado sus actividades constituye un incumplimiento grave, persistente y doloso de las disposiciones fundamentales del contrato, de la Parte XI, del Acuerdo y de las normas, reglamentos y procedimientos. El incumplimiento de otras disposiciones del contrato pueden dar lugar a la imposición de sanciones monetarias. Como garantía para el contratista, la Autoridad no podrá ejecutar ninguna decisión que implique sanciones hasta que se haya dado al contratista una oportunidad razonable de agotar los recursos judiciales de que dispone en virtud de la Convención ${ }^{49}$.

c) Promoción de la investigación científica marina y la transferencia de tecnología

La investigación científica marina desempeña un papel fundamental en la gestión responsable de los océanos y sus recursos. Este tipo de investigación es vital para el progreso científico y la realización de actividades en la Zona de manera eficaz, eficiente y sostenible desde el punto vista comercial y ambiental $^{50}$. La investigación científica marina en la Zona está sometida al principio de libertad, de forma que todos los Estados Partes pueden realizar investigaciones científicas. La Parte XI no contiene otro límite a ese ejercicio de libertad que su realización exclusivamente con fines pacíficos y en beneficio de toda la humanidad y teniendo razonablemente en cuenta las actividades de exploración y explotación. Los Estados tienen, a su vez, el deber de promover la cooperación internacional en la investigación científica marina participando en programas internacionales y velando por que se elaboren programas por conducto de la Autoridad o de otras organizaciones internacionales en beneficio de los Estados en desarrollo y de los Estados tecnológicamente menos avanzados ${ }^{51}$.

El Acuerdo señaló que la investigación científica en la Zona es una de las prioridades de la Autoridad, en particular para garantizar la adquisición de

\footnotetext{
49 Art. 18, Anexo III, Convención.

50 Plan Estratégico, párr. 15.

${ }^{51}$ Arts. 143 (1) (3), 147 (3) y 256, Convención.
} 
conocimientos científicos $^{52}$. Si bien es cierto que la Autoridad no es competente para organizar y controlar las actividades de investigación científica marina en la Zona, está facultada para realizar directamente investigaciones científicas relativas a la Zona y sus recursos y celebrar contratos a ese efecto ${ }^{53}$. Pero además, tiene la función de promover y fomentar la realización de investigaciones científicas y coordinar y difundir los resultados obtenidos, haciendo especial hincapié en las investigaciones relativas a los efectos ambientales de las actividades realizadas en la Zona ${ }^{54}$.

Es preciso destacar la importancia de la cooperación de la Autoridad con otros órganos y organizaciones internacionales competentes en materia de investigación científica marina ${ }^{55}$. En aplicación de su plan estratégico y su plan de acción se está ocupando de fortalecer la cooperación con la Comisión Oceanográfica Internacional (COI), la Organización de las Naciones Unidas para la Educación, la Ciencia y la Cultura (UNESCO), el Organismo Internacional de la Energía Atómica (OIEA) y la Organización Hidrográfica Internacional, así como con la iniciativa de programación conjunta de la Unión Europea sobre mares y océanos sanos y productivos (JPI Oceans) ${ }^{56}$.

Asimismo, la Autoridad está obligada a tomar medidas para adquirir tecnología y conocimientos científicos relacionados con las actividades en la Zona y garantizar una variedad de mecanismos para el desarrollo de la capacidad y la transferencia de tecnología a los Estados en desarrollo. En consonancia con ello, los Estados deben cooperar activamente con las organizaciones internacionales competentes y con la Autoridad para impulsar y facilitar la transmisión de conocimientos prácticos y tecnología marina con respecto a las actividades en la Zona a los Estados en desarrollo, a sus nacionales y a la Empresa ${ }^{57}$.

\footnotetext{
52 Secc. (1) (5) (i), Anexo, Acuerdo.

${ }^{53}$ Art. 143 (2), Convención.

${ }^{54}$ Art. 143 (2), Convención; Secc. 1 (5) (h), Anexo, Acuerdo.

55 Orientación estratégica 4 del Plan Estratégico y el Plan de Acción. Véase también la importancia de la cooperación en materia de investigación científica marina en el contexto de la elaboración de los planes de gestión ambiental, ISBA/17/LTC/7, 13 de julio de 2011: "La Autoridad reconoce la necesidad de trabajar en colaboración con los numerosos procesos y organizaciones internacionales relacionados con la protección del medio marino", párr. 12.

56 Orientación estratégica 4.3.

${ }^{57}$ Arts. 144 (1) (a), 273 y 274, Convención.
} 
El Acuerdo especifica que en la etapa inicial, hasta que comience la etapa de explotación, la Autoridad deberá adquirir conocimientos y tecnología relacionada con la protección y preservación del medio marino. Tras suprimir la obligación de los contratistas de transferir tecnología a la Empresa, el Acuerdo prevé que si la Empresa o los Estados en desarrollo no pueden obtener tecnología para la explotación minera de los fondos marinos - en el mercado abierto o a través de empresas conjuntas - la Autoridad tiene la facultad de pedir a todos o a cualquiera de los contratistas y al Estado o a los Estados patrocinadores respectivos que cooperen con ella para facilitar su adquisición según modalidades y condiciones comerciales equitativas y razonables, compatibles con la protección eficaz de los derechos de propiedad intelectual ${ }^{58}$.

\section{Etapa inicial: la exploración de los minerales de la Zona}

a) El sistema paralelo y los arreglos de empresas conjuntas

Según la Parte XI las actividades de exploración y explotación son realizadas por los Estados Partes o los contratistas por ellos patrocinados y por la Empresa, según el denominado sistema paralelo ${ }^{59}$. La Empresa fue diseñada en la Convención con una naturaleza excepcional en el sentido de que es un órgano de la Autoridad, pero además ha sido concebida para participar directamente en las actividades de exploración y explotación, así como en el trasporte, tratamiento y comercialización de los minerales extraídos de la Zona $^{60}$. Aunque la Empresa debe actuar de conformidad con la política general de la Asamblea y las directivas del Consejo, goza de autonomía en la realización de sus operaciones. La Empresa también tiene que desempeñar la función de facilitar la participación de los Estados en desarrollo en la explotación minera, puesto que puede llevar a cabo esas actividades de minería en las áreas reservadas en asociación con Estados en desarrollo61.

\footnotetext{
58 Secc. 1 (5) (i) y Secc. 5 (1) (b), Anexo, Acuerdo; Orientaciones estratégicas 2.3, 6.3.

${ }^{59}$ Art. 153 (2), Convención.

${ }^{60}$ Art. 170 (1), Convención.

61 Art. 2, Anexo IV; Art. 8, Anexo III, Convención.
} 
El Acuerdo emendó en la práctica el sistema paralelo al disponer que la Empresa llevará a cabo sus actividades iniciales de explotación por medio de empresas conjuntas y que no funcionará de forma independiente de la Secretaría hasta que lo decida el Consejo. Está previsto que el Consejo se ocupe de la cuestión del funcionamiento independiente de la Empresa al aprobarse el primer plan de trabajo para la explotación o al recibir una solicitud de constitución de empresa conjunta con la Empresa ${ }^{62}$. Por tanto, durante esta etapa inicial, sólo los Estados Partes, empresas estatales o personas naturales o jurídicas patrocinadas por ellos han realizado actividades en la Zona .

\section{b) Las actividades de prospección y exploración}

Las actividades de prospección consisten en la búsqueda de yacimientos de minerales, incluida la estimación de la composición, el tamaño y la distribución de esos yacimientos y su valor económico. Al no conferir la prospección derechos exclusivos sobre los recursos, no se exige al prospector la conclusión de un contrato con la Autoridad, basta una notificación con los límites aproximados del área o las áreas en que vaya a realizar la prospección junto con un compromiso satisfactorio por escrito de que el futuro prospector cumplirá la Convención y la normativa aprobada por la Autoridad, concernientes a la cooperación en los programas de capacitación en ciencia marina y técnica y a la protección del medio marino ${ }^{63}$. La prospección solo podrá comenzar una vez que el Secretario General haya informado al prospector de que su notificación ha sido registrada ${ }^{64}$.

\footnotetext{
62 Secc. 2, Anexo. El 27 de abril de 2018 el Secretario General recibió en una carta del Secretario de Estado del Ministerio de Medio Ambiente del Gobierno de Polonia expresando interés para celebrar negociaciones encaminadas a constituir una empresa conjunta con la Empresa. El Secretario General ha nombrado temporalmente un Representante Especial para llevar adelante dichas negociaciones en espera a que el Consejo de pronuncie sobre el nombramiento de un Director General Interino de entre el personal de la Autoridad, de conformidad con la Sección 2 (1) del Anexo. Véase el Informe presentado por el Representante Especial durante la segunda parte del $25^{\circ}$ período de sesiones del Consejo, E. Egede/M. Pal/E. Charles, A Study on Issues Related to the Operationalization of the Enterprise in particular on the Legal, Technical and Financial Implications for the International Seabed Authority and for States Parties to the United Nations Convention on the Law of the Sea, 13 June 2019.

${ }^{63}$ Arts. 2.2, 2.1 (b), Anexo III, Convención.

${ }^{64}$ Art. 2 (1), Reglamento sobre nódulos polimetálicos; Art. 2 (5), Reglamento sobre sulfuros polimetálicos; Art. 2 (5), Reglamento sobre costras de ferromanganeso.
} 
Por exploración se entiende la búsqueda de yacimientos de minerales en la Zona en virtud de derechos exclusivos, el análisis de esos yacimientos, la utilización y el ensayo de sistemas y equipo de recuperación, instalaciones de tratamiento y sistemas de transporte y la realización de estudios de factores ambientales, técnicos, económicos y comerciales y otros factores apropiados que haya de tener en cuenta en la explotación ${ }^{65}$. Los solicitantes de un plan de trabajo para la exploración deberán presentar un certificado de patrocinio expedido por el Estado de su nacionalidad o a cuyo control esté efectivamente sujeta, así como información suficiente que acredite su capacidad financiera y técnica para realizar las actividades de exploración propuestas y para cumplir sus obligaciones financieras con la Autoridad ${ }^{66}$.

El patrocinio tiene una enorme relevancia jurídica en el sistema de exploración y explotación. El propósito de exigir el patrocinio a los solicitantes de contratos de exploración y explotación es lograr que se cumplan las obligaciones establecidas en la Convención, exigibles solo a los Estados Partes en la misma, por entidades que son sujetos de los derechos nacionales. Este resultado se obtiene a través de las disposiciones reglamentarias de la Autoridad que se aplican a dichas entidades y a través del cumplimiento por parte de los Estados patrocinadores de sus obligaciones bajo la Convención y los instrumentos $\operatorname{conexos}^{67}$. Es más, como ha indicado la Sala de Controversias en su opinión consultiva:

“El papel del Estado patrocinador, tal como se establece en la Convención, contribuye a la realización del interés común de todos los Estados en la aplicación adecuada del principio del patrimonio común de la humanidad, que requiere el cumplimiento fiel de las obligaciones establecidas en la Parte $\mathrm{Xl}{ }^{\prime \prime 8}$.

Una vez aprobado por el Consejo el plan de trabajo para la exploración se prepara en forma de contrato entre la Autoridad y el solicitante por una duración de 15 años prorrogable. El contratista tendrá el derecho exclusivo de explorar el área abarcada por el plan de trabajo respecto de los minerales

\footnotetext{
${ }^{65}$ Art. 1 Reglamento sobre nódulos polimetálicos; Art. 1 (3) (b), Reglamento sobre sulfuros polimetálicos; Art. 1 (3) (b), Reglamento sobre costras de ferromanganeso.

${ }_{66}$ Arts. 11 y 12, Reglamento sobre nódulos polimetálicos; Art. 11 y 13, Reglamento sobre sulfuros polimetálicos; Art. 11 y 13, Reglamento sobre costras de ferromanganeso.

${ }^{67}$ Advisory Opinion, párr. 75.

68 Ibíd., párr. 76.
} 
solicitados. La Autoridad tiene la obligación de velar por que ninguna otra entidad realice en la misma área actividades relacionadas con los recursos de forma tal que pueda dificultar las operaciones del contratista. Por último, todos los contratos deben incluir en un anexo un programa de capacitación del personal de la Autoridad y de los Estados en desarrollo ${ }^{69}$. Hasta la fecha la Autoridad ha celebrado 17 contratos para la exploración de nódulos polimetálicos, 7 contratos para la exploración de sulfuros polimetálicos y 5 contratos para la exploración de costras de ferromanganeso con alto contenido de cobalto en varias áreas geográficas de la Zona ${ }^{70}$.

\section{LA PROTECCIÓN DEL MEDIO MARINO CONTRA LOS EFECTOS DERIVADOS DE LAS ACTIVIDADES EN LA ZONA}

\section{Marco jurídico}

Las disposiciones de la Convención relativas a la protección del medio marino contra los efectos derivados de las actividades en la Zona son escasas, estableciendo un marco jurídico insuficiente que la Autoridad tiene el deber de desarrollar a través de su facultad reglamentaria. De esta forma empieza a dibujarse lo que será una nueva política ambiental internacional en un sector caracterizado por una gran incertidumbre científica, técnica y comercial ${ }^{71}$. El artículo 209 (1) dispone que se establecerán normas, reglamentos y procedimientos internacionales para prevenir, reducir y controlar la contaminación del medio marino resultante de actividades en la Zona y que tal reglamentación se reexaminará con la periodicidad necesaria. El artículo 145

\footnotetext{
${ }^{69}$ Reglas 23, 24, 26, Reglamento sobre nódulos polimetálicos; Reglas 25, 26 y 28, Reglamento sobre sulfuros polimetálicos; Reglas 25, 26 y 28, Reglamento sobre costras de ferromanganeso 70 Véase ISBA/25/LTC/2, Anexo II, 25 de mayo de 2017.

${ }^{71}$ Informe del Secretario General, Examen del proyecto estratégico de la Autoridad Internacional de los Fondos Marinos para el período 2019 - 2023 a los efectos de su aprobación, ISBA/24/A/4, 21 de mayo de 2018, párr. 14. Sobre el posible impacto de la minería oceánica en el medio marino véase J. M. Durden (et al), "Environmental Impact Assesment process for deep-sea mining in the Area", Marine Policy, 87 (2018) pp. 194-202; K. A. Miller (et al), "An Overview of Seabed Mining Including the Current State of Development, Environmental Impacts and Knowledge Gaps", Frontiers in Marine Science, vol. 4, Article 418; R. Shama, "Environmental Issues of Deep-Sea Mining", Procedia Earth and Planetary Science January 2018, 11 (2015) pp. 204 - 211; E. Simon-Lledó, "Biological effects 26 years after simulated deep-sea mining", Scientific Reports (2019) 9:8040; T. W. Washburn (et al), "Ecological risk assessment for deep-sea mining", Ocean and Coastal Management 176 (2019) pp. 24-39.
} 
establece que se adoptarán las medidas necesarias para asegurar la "eficaz protección del medio marino" contra los efectos nocivos que puedan resultar de las actividades en la Zona. Esta disposición atribuye a la Autoridad una competencia muy amplia en materia de medio ambiente que comprende el mandato de establecer normas, reglamentos y procedimientos apropiados para prevenir, reducir y controlar la contaminación del medio marino, así como, proteger y conservar los recursos naturales de la Zona y prevenir daños a la flora y fauna marinos ${ }^{72}$.

El Acuerdo reafirmó la importancia de la Convención para la protección y preservación del medio marino y señaló que en la etapa inicial la Autoridad daría prioridad a la adopción de normas, reglamentos y procedimientos que incorporasen estándares aplicables sobre la protección y preservación del medio marino ${ }^{73}$. La opinión consultiva de la Sala de Controversias ha permitido clarificar las obligaciones y responsabilidades de los actores implicados en materia ambiental. Y, por último, hay que destacar que los principios ambientales han sido incorporados como principios rectores, junto al principio de $\mathrm{PCH}$, al Plan estratégico de la Autoridad.

De todo ello se deduce que una política ambiental integrada, bien estructurada y coherente es absolutamente necesaria antes del inicio de las actividades de explotación ${ }^{74}$. En este sentido es de destacar el papel fundamental de la CJT que tiene importantes competencias en materia de protección del medio marino: debe preparar evaluaciones de las consecuencias ecológicas de las actividades en la Zona; hacer recomendaciones al Consejo acerca de la protección del medio marino teniendo en cuenta las opiniones de expertos reconocidos; elaborar y someter al Consejo normas, reglamentos y procedimientos ambientales teniendo en cuenta la evaluación de las consecuencias ecológicas de las actividades en la Zona; mantener a examen esas normas, reglamentos y procedimientos recomendando al Consejo las enmiendas necesarias; hacer recomendaciones al Consejo con respecto al

\footnotetext{
72 Art. 145 y Art. 17 (1) (b) (xii), Anexo III, Convención; Regla 31 (1) Reglamento sobre nódulos polimetálicos; Regla 33 (1) Reglamento sobre sulfuros polimetálicos; Regla 33 (1) Reglamento sobre costras de ferromanganeso.

${ }^{73}$ Preámbulo; Secc. 1 (5) (g) Anexo, Acuerdo.

${ }^{74}$ Véase al respecto A. Jaeckel, "An Environmental Management Strategy for the International Seabed Authority? The Legal Basis, The International Journal of Marine and Coastal Law, 30 (2015) pp. $93-119$.
} 
establecimiento de un programa de vigilancia para observar, medir, evaluar y analizar en forma periódica, mediante métodos científicos reconocidos, los riesgos o las consecuencias de las actividades en la Zona en lo relativo a la contaminación del medio marino, asegurarse de que la reglamentación vigente sea adecuada y se cumpla, y coordinar la ejecución del programa de vigilancia una vez aprobado por el Consejo ${ }^{75}$. A este respecto, resulta evidente la importancia de que entre sus miembros se encuentren expertos cualificados en materia ambiental ${ }^{76}$.

\section{Principios ambientales aplicados a las actividades en la Zona}

\section{a) El principio de utilización sostenible de los recursos}

La humanidad, en cuanto conjunto de todos los seres humanos, presenta un marcado carácter prospectivo, en la medida en que engloba igualmente a las futuras comunidades humanas. Este sentido prospectivo presenta asimismo una evidente relación con la noción de patrimonio común, pues implica su preservación para las generaciones venideras ${ }^{77}$. El principio de $\mathrm{PCH}$ está estrechamente ligado a uno de los principios generales del derecho internacional del medio ambiente, el desarrollo sostenible, y más concretamente con la idea de equidad intergeneracional recogida en el Principio 3 de la Declaración de Río ${ }^{78}$. De hecho, el desarrollo del patrimonio común en beneficio de toda la humanidad lleva consigo el equilibrio entre los tres pilares del desarrollo sostenible: el ambiental, el social y el económico ${ }^{79}$.

El principio de utilización sostenible de los recursos se encuentra en la Convención sólo de forma embrionaria, porque en el momento de su negociación no se prestó suficiente atención a las preocupaciones ambientales. Aún así, se incluyó el mandato a la Autoridad de asegurar la administración

\footnotetext{
${ }^{75}$ Art. 165 (2) (d) (e) (f) (g) (h), Convención.

${ }^{76}$ Véase Informe final sobre el examen periódico de la Autoridad Internacional de los Fondos Marinos con arreglo al artículo 154 de la Convención de las Naciones Unidas sobre el Derecho del Mar, ISBA/23/A/3, 8 de febrero de 2017, párr. 15.

${ }^{77}$ E. Salamanca Aguado, La Zona internacional... cit., p. 313.

78 "El derecho al desarrollo debe ejercerse en forma tal que responda equitativamente a las necesidades de desarrollo y ambientales de las generaciones presentes y futuras".

${ }^{79}$ Dirección estratégica 1.3.
} 
ordenada, segura y racional de los recursos de la Zona, incluida la realización eficiente de las actividades $y$, de conformidad con sólidos principios de conservación, la evitación de desperdicios innecesarios. Del mismo modo, debe proteger y conservar los recursos naturales que constituyen el $\mathrm{PCH}^{80}$. La Autoridad ha tenido en cuenta la Agenda 2030 para el Desarrollo Sostenible ${ }^{81}$ en la elaboración del Plan estratégico y su Plan de Acción y la promoción de una administración ordenada, segura y racional de los recursos de la Zona en beneficio de toda la humanidad se encuentra entre sus principios rectores ${ }^{82}$. En esta línea se ha comprometido con la realización de los ODS, en particular con el ODS 14 "Conservar y utilizar en forma sostenible los océanos, los mares y los recursos marinos para el desarrollo sostenible", contribuyendo al aumento de los conocimientos científicos, desarrollando la capacidad de investigación, transfiriendo tecnología marina y promoviendo un criterio común y uniforme, de conformidad con la Convención y el derecho internacional, para la uso sostenible de los recursos oceánicos ${ }^{83}$.

\section{b) El principio de prevención del daño ambiental}

El principio de prevención del daño ambiental está firmemente establecido en el derecho internacional del medio ambiente. En el asunto Iron Rhine de 24 de mayo de 2005, el tribunal arbitral reconoció que donde el desarrollo puede causar un daño significativo al medio ambiente, existe el deber de prevenir, o al menos mitigar, dicho daño y que dicho deber de prevenir el daño ambiental se ha convertido en un principio de derecho internacional general ${ }^{84}$. En el principio 2 de la Declaración de Rio se formula como una responsabilidad de los Estados de velar por que las actividades realizadas dentro de su jurisdicción o bajo su control no causen daños al medio ambiente de otros Estados o de

\footnotetext{
${ }^{80}$ Arts. 150 (b) y 145 (b), Convención.

${ }^{81}$ A/RES/70/1, 21 de octubre de 2015.

${ }^{82}$ Plan estratégico, I. 6 (c).

${ }^{83}$ Véase "Contribución de la Autoridad Internacional de los Fondos Marinos a la consecución de los Objetivos de Desarrollo Sostenible", ISBA/24/A/10, Apéndice I. Véanse también los compromisos voluntarios de la Autoridad en relación con el ODS 14 en $<$ https://www.isa.org.jm/isa-voluntary-commitments> [Última visita: 15 de octubre de 2019].

${ }_{84}$ Award in the Arbitration regarding the Iron Rhine ("Ijzeren Rijn") Railway between the Kingdom of Belgium and the Kingdom of the Netherlands, decision of 24 May 2005, párr. 55.
} 
zonas que estén fuera de los limites de la jurisdicción nacional ${ }^{85}$. En el dictamen relativo a la licitud de la amenaza o el empleo de armas nucleares de 8 de julio de 1996 la Corte Internacional de Justicia (CIJ) reconoció que esta obligación general forma parte ya del corpus de normas internacionales de medio ambiente ${ }^{86}$.

De la aplicación de este principio de prevención del daño ambiental a las actividades en la Zona se derivan una serie de obligaciones para la Autoridad, los Estados patrocinadores y los contratistas.

i) Obligación de prevenir, reducir y controlar la contaminación del medio marino

El artículo 192 dispone que los Estados Partes tienen la obligación general de proteger y preservar el medio marino. Entre las obligaciones específicas que asumen los Estados Partes se encuentra la de prevenir, reducir y controlar la contaminación del medio marino procedente de cualquier fuente, vigilar los riesgos de contaminación o sus efectos y evaluar los efectos potenciales de las actividades bajo la jurisdicción y el control de los Estados Partes que pueden causar una contaminación considerable del medio marino u ocasionar cambios importantes y perjudiciales en él ${ }^{87}$. Entre las medidas que deberán adoptarse se encuentran las necesarias para proteger y preservar los ecosistemas raros o vulnerables, así como el hábitat de las especies y otras formas de vida marina diezmadas, amenazadas o en peligro ${ }^{88}$. También deben prevenir, reducir y controlar la contaminación causada por la utilización de tecnologías bajo su jurisdicción o control y la introducción intencional o accidental en un sector determinado del medio marino de especies extrañas o nuevas que puedan

\footnotetext{
85 Declaración adoptada en la Conferencia de las Naciones Unidas sobre Medio Ambiente y Desarrollo (Cumbre de la Tierra), Río de Janeiro, 3 al 14 de junio de 1992.

${ }^{86}$ Legality of the Threat or Use of Nuclear Weapons, Advisory Opinion, I.C.J. Reports 1996 (I), párr. 29.

${ }^{87}$ Arts. 194 (1), 204 (1) y 206 (1), Convención.

${ }^{88}$ Art. 194 (5), Convención.
} 
causar en él cambios considerables y perjudiciales ${ }^{89}$. Además, el artículo 194 (2) recoge la obligación de prevenir el daño ambiental transfronterizo ${ }^{90}$.

Estas obligaciones generales son de aplicación a las actividades en la Zona en relación a los Estados Partes. Pero además, en virtud de los reglamentos aprobados por la Autoridad, otros actores - no sujetos de derecho internacional y, por tanto, no obligados directamente por normas convencionales - asumen estas mismas obligaciones generales. Los prospectores y contratistas tienen el deber de adoptar las medidas necesarias para prevenir, reducir y controlar, en la medida de lo razonablemente posible, la contaminación y otros riesgos para el medio marino derivados de las actividades en la Zona91. Los contratistas deben además tomar las medidas necesarias para garantizar que sus actividades se realizan de tal forma que no causen daños graves al medio marino bajo la jurisdicción o soberanía de otros Estados ribereños, contaminación entre otros, y que los daños graves o la contaminación causados por incidentes o actividades en su zona de exploración no se extiendan más allá de dicha zona ${ }^{92}$.

ii) Obligación de evaluar el impacto ambiental

La obligación de hacer una evaluación de los efectos sobre el medio marino fue introducida por la sección 1 (7) del Anexo del Acuerdo. Según esta disposición toda solicitud de aprobación de un plan de trabajo irá acompañada de una evaluación de los posibles efectos sobre el medio ambiente de las actividades propuestas. Según los reglamentos esta evaluación de los posibles efectos ambientales de las actividades propuestas por los contratistas se realizan en dos momentos diferentes, en el momento de presentar el plan de trabajo para

\footnotetext{
${ }^{89}$ Art. 196 (1), Convención.

90 "Los Estados tomarán todas las medidas necesarias para garantizar que las actividades bajo su jurisdicción o control se realicen de forma tal que no causen perjuicios por contaminación a otros Estados y su medio ambiente, y que la contaminación causada por incidentes o actividades bajo su jurisdicción o control no se extienda más allá de las zonas donde ejercen derechos de soberanía de conformidad con esta Convención".

${ }^{91}$ Reglas 5 (1) y 31 (5) Reglamento sobre nódulos polimetálicos; Reglas 5 (1) y 33 (5), Reglamento sobre sulfuros polimetálicos; Reglas 5 (1) y 33 (5), Reglamento sobre costras de ferromanganeso. En el caso de los prospectores - que no firman un contrato con la Autoridad se les exige además reducir al mínimo o eliminar los efectos ambientales adversos de la prospección.

92 Regla 34 (4) Reglamento sobre nódulos polimetálicos; Regla 36 (4), Reglamento sobre sulfuros polimetálicos; Regla 36 (4), Reglamento sobre costras de ferromanganeso.
} 
su aprobación en forma de contrato y una vez firmado el contrato de exploración con la Autoridad pero antes de iniciar las actividades de exploración.

El solicitante de un plan de trabajo para la exploración deberá presentar una descripción del programa de estudios oceanográficos y ambientales de referencia que permitan hacer una evaluación de los posibles efectos sobre el medio ambiente, incluidos entre otros, los efectos sobre la biodiversidad de las actividades de exploración propuestas, teniendo en cuenta las recomendaciones de la CJT. Deberán asimismo presentar una evaluación preliminar de los posibles efectos sobre el medio ambiente y una descripción de las medidas propuestas para prevenir, reducir y controlar la contaminación y otros riesgos para el medio marino, así como los posibles efectos sobre él ${ }^{93}$.

La CJT tiene una responsabilidad fundamental en la prevención de los daños ambientales. En primer lugar, deberá examinar la solicitud y comprobar que contiene disposiciones relativas a la protección y preservación del medio marino, incluidos, los efectos sobre la biodiversidad ${ }^{94}$. En segundo lugar, deberá establecer y aplicar procedimientos para determinar, sobre la base de la mejor información científica y técnica disponible, incluida la proporcionada por los contratistas en su plan de trabajo, si las actividades de exploración propuestas tendrían efectos nocivos graves en los ecosistemas marinos vulnerables, en este caso, deberá cerciorarse de que se procede a una ordenación de esas actividades destinada a prevenir esos efectos o no se autorice su realización ${ }^{95}$.

Los contratos de exploración exigen a los contratistas que recopilen datos oceanográficos y ambientales de referencia y establezcan líneas de bases ambientales para evaluar los efectos probables en el medio marino de su programa de actividades de conformidad con el plan de trabajo para la exploración y un programa de vigilancia e información respecto de esos

\footnotetext{
${ }^{93}$ Reglas 18 (b) (c) (d) Reglamento sobre nódulos polimetálicos; Reglas 20 (1) (b) (c) (d) Reglamento sobre sulfuros polimetálicos; Reglas 20 (1) (b) (c) (d) Reglamento sobre costras de ferromanganeso.

${ }_{94}$ Regla 21 (4) (b) Reglamento sobre nódulos polimetálicos; Regla 23 (4) (b) Reglamento sobre sulfuros polimetálicos; Regla 23 (4) (b) Reglamento sobre costras de ferromanganeso.

${ }_{95}$ Regla 31 (4) Reglamento sobre nódulos polimetálicos; Regla 33 (4) Reglamento sobre sulfuros polimetálicos; Regla 33 (4) Reglamento sobre costras de ferromanganeso.
} 
efectos. El contratista cooperará con la Autoridad y el Estado o los Estados patrocinadores en la formulación y ejecución del programa de vigilancia e informará anualmente al Secretario General de la aplicación y los resultados de sus programas de vigilancia ambiental ${ }^{96}$.

De nuevo es destacable el rol fundamental de la CJT, que puede formular recomendaciones de índole técnica o administrativa que sirvan como directrices a los contratistas a fin de ayudarles en la aplicación de los reglamentos $^{97}$. La CJT ha publicado una revisión actualizada de sus recomendaciones con respecto a la evaluación de los posibles efectos ambientales de la exploración de minerales marinos en la Zona ${ }^{98}$. Sus consideraciones ambientales se basan en el uso de un tipo de tecnología que presumiblemente es la que utilizan los contratistas, esto es, la remoción mecánica sin procesamiento inicial en el fondo marino. Está previsto que en el futuro puedan utilizarse otro tipo de tecnologías que exijan una actualización de las recomendaciones. En ellas se describen los procedimientos que habrán de seguirse en la adquisición de los datos de referencia y la vigilancia que deberá llevarse a cabo durante las actividades de exploración y que puedan causar daños graves al medio marino. En concreto persigue definir las propiedades oceanográficas, químicas, geológicas, biológicas y sedimentarias que deberán medirse y procedimientos que deben seguirse, facilitar la presentación de los informes por los contratistas y proporcionar orientación a futuros contratistas en la elaboración de los planes de trabajo ${ }^{99}$.

Pero además no sólo se trata de una obligación de los contratistas sino que la Sala de Controversias ha entendido que el Estado patrocinador tiene la obligación de procurar que el contratista patrocinado por él cumpla su obligación y que la obligación de realizar una evaluación de impacto ambiental es también una obligación directa del Estado patrocinador en virtud del artículo

\footnotetext{
${ }^{96}$ Regla 32 (1) (2) Reglamento sobre nódulos polimetálicos; Regla 34 (1) (2) Reglamento sobre sulfuros polimetálicos; Regla 34 (1) (2) Reglamento sobre costras de ferromanganeso.

97 Regla 39, Reglamento sobre nódulos polimetálicos; Regla 41, Reglamento sobre sulfuros polimetálicos; Regla 41, Reglamento sobre costras de ferromanganeso.

98 ISBA/25/LTC/6, 18 de abril de 2019.

99 Ibíd., párrs. 8 y 9 . El Anexo I contiene un comentario explicativo con información detallada que incluye un glosario de términos técnicos. Sorprende, sin embargo, que sólo están disponibles al público dos informes de evaluación ambiental, los presentados por los contratistas patrocinados por Bélgica y Alemania, circunstancia que es denunciada reiteradamente por las organizaciones ecologistas.
} 
206 y del derecho internacional consuetudinario. Serán las reglas contenidas en los reglamentos de la Autoridad y las indicaciones de las recomendaciones de la CJT sobre la materia las que añadan precisión y especificidad a la obligación de realizar una evaluación del impacto ambiental en el contexto de las actividades en la Zona ${ }^{100}$.

iii) Obligación de adoptar órdenes y medidas de emergencia

El Consejo, en tanto que órgano ejecutivo de la Autoridad, está facultado para expedir órdenes de emergencia que podrán incluir la suspensión o el reajuste de las operaciones, a fin de impedir daños graves al medio marino como consecuencia de las actividades en la Zona ${ }^{101}$. Si un contratista no cumple prontamente una orden de emergencia para impedir, contener o reducir al mínimo daños graves o la amenaza de daños graves al medio marino derivados de sus actividades en la Zona, el Consejo adoptará, por sí mismo o mediante mecanismos concertados en su nombre con terceros, las medidas de emergencia que sean necesarias. A fin de que el Consejo pueda adoptar inmediatamente dichas medidas, el contratista dará al Consejo una garantía de su capacidad financiera y técnica de cumplir rápidamente las órdenes de emergencia o de asegurar que el Consejo pueda adoptar ese tipo de medidas de emergencia. Si el contratista no diese al Consejo una garantía de esa naturaleza, el Estado patrocinador deberá, en respuesta a una petición del Secretario General, adoptar las medidas necesarias para asegurar que el contratista dé dicha garantía o adoptar medidas para asegurar que dicha asistencia se suministre a la Autoridad en el cumplimiento de sus obligaciones $^{102}$. Se trata, de nuevo, de una obligación directa que incumbe a los Estados patrocinadores ${ }^{103}$.

c) El principio de precaución y las mejores prácticas ambientales

\footnotetext{
${ }^{100}$ Advisory Opinion, párr. 149.

${ }^{101}$ Art. $162(2)(w)$, Convención.

102 Reglas 33 (7) (8) Reglamento sobre nódulos polimetálicos; Reglas 35 (7) (8) Reglamento sobre sulfuros polimetálicos; Reglas 35 (7) (8) Reglamento sobre costras de ferromanganeso ${ }^{103}$ Advisory Opinion, párr. 138.
} 
El principio o criterio de precaución ${ }^{104}$ tiene como objetivo proporcionar orientación en el desarrollo y aplicación del derecho internacional del medio ambiente cuando exista falta de certidumbre científica ${ }^{105}$. A través de su facultad reglamentaria la Autoridad ha dispuesto que para asegurar la protección eficaz del medio marino contra los efectos nocivos que puedan derivarse de las actividades en la Zona, ella misma y los Estados patrocinadores aplicarán el criterio de precaución que figura en el Principio 15 de la Declaración de Río y las mejores prácticas ambientales ${ }^{106}$. La Sala de Controversias ha dictaminado que las disposiciones de los reglamentos aprobados por la Autoridad han transformado el enunciado no vinculante del criterio de precaución en una obligación vinculante y que se trata tanto de una obligación directa de los Estados patrocinadores como un elemento de la obligación de actuar con la diligencia debida ${ }^{107}$. Por su parte, la CJT deberá hacer recomendaciones al Consejo sobre la aplicación de estas obligaciones $^{108}$.

El alcance del criterio de precaución en su aplicación a las actividades en la Zona está determinado por su formulación en la Declaración de Rio ${ }^{109}$. Es

\footnotetext{
${ }^{104}$ La Secretaría de la Autoridad ha indicado que el uso del término "principio" o "criterio" en el contexto del principio 15 de la Declaración de Río es una cuestión semántica y no plantea una diferencia significativa de contenido e intención. Nota de la Secretaría, Aplicación del criterio de precaución a las actividades realizadas en la Zona, ISBA/25/C/8, párr. 11.

105 P. Sands / J. Peel, Principles of International Environmental Law, Cambridge University Press, 2018, p. 230.

106 Regla 31 (2) Reglamento sobre nódulos polimetálicos; Regla 33 (2) Reglamento sobre sulfuros polimetálicos; Regla 33 (2) Reglamento sobre costras de ferromanganeso. Los reglamentos no definen qué debe entenderse por mejores prácticas ambientales, aunque esta laguna se subsanará en el futuro reglamento de explotación de recursos minerales de la Zona, en el que se incluye una definición al respecto: "se entiende la aplicación de la combinación más adecuada de medidas y estrategias de control ambiental, que varían con el tiempo a la luz de la mejora de los conocimientos, la comprensión o la tecnología, teniendo en cuenta las orientaciones establecidas en las directrices aplicables", ISBA/25/C/WP.1, 22 de marzo de 2019, Adenda.

107 Advisory Opinion, párrs. 125, 127 y 131. La Sala se apoya para vincular la obligación de diligencia debida con el criterio de precaución en la Orden de 27 de agosto de 1999 del TDM en el Tuna cases (ITLOS Reports 1999, p. 274, para. 77), ibíd., párr. 132.

108 Regla 31 (3), Reglamento sobre nódulos polimetálicos; Regla 33 (3), Reglamento sobre sulfuros polimetálicos; Regla 33 (3), Reglamento sobre costras de ferromanganeso.

${ }^{109}$ El Principio 15 de la Declaración de Río formuló el principio de precaución como un criterio (approach) en términos muy restringidos: "Con el fin de proteger el medio ambiente, los Estados deberán aplicar ampliamente el criterio de precaución conforme a sus capacidades. Cuando haya peligro de daño grave o irreversible, la falta de certeza científica absoluta no deberá utilizarse como razón para postergarla adopción de medidas eficaces en función de los costos para impedir la degradación del medio ambiente".
} 
decir, se limita a los supuestos de peligro de daño grave o irreversible ${ }^{110}$, las medidas a adoptar serán eficaces en función de los costos, su finalidad será la de impedir la degradación del medio marino y los Estados deben aplicar el criterio de precaución conforme a sus capacidades ${ }^{111}$. Además, las obligaciones de aplicar el criterio de precaución y las mejores prácticas ambientales son también exigibles a los contratistas en virtud del contrato ${ }^{112}$. Por tanto, el criterio de precaución es una obligación contractual de los contratistas patrocinados cuyo cumplimiento tiene la responsabilidad de garantizar el Estado patrocinador ${ }^{113}$.

En el contexto de las actividades de la Zona se entiende que el criterio de precaución
"promueve fundamentalmente una toma de decisiones mejorada e informada. Aunque esa toma de decisiones debe basarse en los mejores conocimientos científicos disponibles, en el criterio se reconoce que dichos conocimientos son incompletos y que, por tanto, se precisan técnicas y medidas para solventar la incertidumbre científica y los riesgos que conlleva" ${ }^{114}$.

El criterio de precaución es además un principio rector del plan estratégico de la Autoridad y se pondrá en práctica aplicando las orientaciones estratégicas y el enfoque basado en riesgos ${ }^{115}$. Además, los planes regionales de gestión ambiental elaborados de conformidad con la política ambiental de la Autoridad ponen en práctica el criterio de precaución ${ }^{116}$. Su aplicación supone la adopción

\footnotetext{
110 Por "daños graves al medio marino" se entiende los efectos que constituyan un cambio adverso importante del medio marino determinado con arreglo a las normas, reglamentos y procedimientos de la Autoridad sobre la base de normas y prácticas internacionalmente reconocidas, Regla 1 (3) (f), Reglamento sobre nódulos polimetálicos; Regla 1 (3) (f), Reglamento sobre sulfuros polimetálicos; Regla 1 (3) (f), Reglamento sobre costras de ferromanganeso.

111 Advisory Opinion, párrs. 128 y 129. La Sala exhorta a la Autoridad a que introduzca el criterio de precaución en el proyecto de reglamento sobre actividades de explotación, ibíd., párr. 130.

${ }_{112}$ Art. 31 (5), Reglamento sobre nódulos polimetálicos; Art. 33 (5), Reglamento sobre sulfuros polimetálicos; Art. 33 (5), Reglamento sobre costras de ferromanganeso.

${ }^{113}$ Advisory Opinion, párr. 133.

114 ISBA/25/C/8, párr. 7.

${ }^{115}$ Nota de la Secretaría, Aplicación del criterio de precaución a las actividades realizadas en la Zona, ISBA/25/C/8, párr. 2.

116 Véase ISBA/18/C/22, párr. 1, en relación con la aprobación del plan de gestión ambiental para la zona de fractura de Clarion-Clipperton.
} 
de medidas que están agrupadas en tres vertientes: institucional, procedimental y de protección ${ }^{117}$. No se trata de medidas aisladas sino componentes del marco normativo que se está desarrollando con respecto a la elaboración de las "medidas necesarias" mencionadas en el artículo 145 para la protección eficaz del medio marino ${ }^{118}$.

\section{i) Vertiente institucional}

Las medidas institucionales se refieren principalmente al fomento de la capacidad y las competencias de la Autoridad en materia de evaluación, supervisión y cumplimiento, y hacen preciso evaluar de manera constante las necesidades de contratación de expertos de la Secretaría y la composición de la CJT conforme cambien las necesidades de la Autoridad ${ }^{119}$. Se incluye también el desarrollo de la capacidad de los Estados en desarrollo ${ }^{120}$, el establecimiento y la cooperación con otras organizaciones y órganos de expertos, y el cumplimiento del compromiso de la Autoridad de lograr los ODS, como modos de generar y ampliar conocimientos para mejorar la toma de decisiones informadas ${ }^{121}$.

\section{ii) Vertiente procedimental}

Las medidas de procedimiento están orientadas a los procesos de toma de decisiones de la Autoridad. La vertiente procedimental abarca la evaluación del riesgo y del grado de aceptabilidad de los posibles efectos perniciosos generados por las actividades de exploración o minería, evaluación que incluye el examen de los conocimientos científicos disponibles y de la incertidumbre de la información científica. En ese sentido, proporcionar acceso a datos e información no confidenciales e impulsar una toma de decisiones transparente y sujeta a rendición de cuentas mediante la participación de los interesados ${ }^{122}$.

\footnotetext{
117 Véase el documento de debate "The implementation of the precautionary approach by the International Seabed Authority", documento de debate núm. 5, marzo de 2017.

118 ISBA/25/C/8, párr. 12.

119 Orientación estratégica 8.

120 Ibíd., 5 y 6.

121 Ibíd., 1.1. y 1.2.

122 Ibíd., 9.
} 
iii) Vertiente de protección

En cuanto a las medidas de protección, la Autoridad está promoviendo su estrategia para la elaboración de planes regionales de gestión ambiental para la Zona, que examinaremos más adelante, y la CJT está trabajando en la definición de un marco de política ambiental global, lo que ayudará a elaborar normas y directrices de desempeño ambiental para fijar metas y objetivos acordes con lo dispuesto en el artículo $145^{123}$.

d) El principio de cooperación: zonas de referencia para los efectos y zonas de referencia para la preservación

Un importante aspecto a destacar de la política ambiental de la Autoridad es la necesidad de adoptar un enfoque global y/o regional en el sentido de que existen medidas ambientales que no serán eficaces si sólo son adoptadas por los contratistas en sus áreas de exploración y que exigen una actuación a nivel de la Autoridad, por ejemplo, en la protección de ecosistemas vulnerables ${ }^{124}$. En este sentido, los reglamentos se refieren al deber de los contratistas de cooperar con la Autoridad y los Estados patrocinadores en la preparación y aplicación de programas para la vigilancia y evaluación de los efectos sobre el medio marino de la extracción de minerales de los fondos marinos. Estos programas incluyen propuestas de zonas que se utilicen exclusivamente como zonas de referencia para los efectos (ZRE) y zonas de referencia para la preservación (ZRP). Las ZRE son las zonas que se utilizan para evaluar los efectos en el medio marino de las actividades en la Zona y que sean representativas de las características ambientales de la Zona. Por el contrario, las ZRP son aquellas en que no se efectuarán extracciones a fin de que la biota

\footnotetext{
${ }^{123}$ Véase Nota de la secretaría. El contenido y la elaboración de normas y directrices para las actividades realizadas en la Zona conforme al marco regulador de la Autoridad, ISBA/25/C/3, 17 de diciembre de 2018.

${ }^{124}$ Véase C. L. Van Dover (et al), "Scientific rationale and international obligations for protection of active hydrothermal vent ecosystems from deep sea mining", Marine Policy, 90 (2018) pp. 20-28.
} 
del fondo marino se mantenga representativa y estable y permita evaluar los cambios que tengan lugar en la biodiversidad del medio marino ${ }^{125}$.

En las recomendaciones se indica que el contratista deberá proporcionar al Secretario General información sobre la demarcación, en relación con la evaluación del impacto de las pruebas de extracción, en dichas zonas. La ZRE deberá ser el lugar donde vayan a tener lugar las pruebas de extracción y los efectos directos relacionados. La ZRP deberá estar en un lugar lo suficientemente lejano como para no verse afectado por las actividades de pruebas, incluidos los efectos de los penachos de descargas y de perturbación del fondo marino. Las ZRP son importantes con miras a determinar las variaciones naturales de las condiciones ambientales que servirán de referencia para evaluar los efectos de las pruebas de extracción. Su composición en cuanto a especies deberá ser comparable a la de las zonas afectadas $^{126}$.

Así mismo, la Autoridad ha reconocido la necesidad de trabajar en colaboración con los procesos y organizaciones internacionales relacionadas con la protección del medio marino ${ }^{127}$.

\section{e) Principio de reparación del daño ambiental}

Como ya se ha indicado, la minería oceánica más allá de la jurisdicción nacional es una actividad que entraña numerosos riesgos para el medio ambiente y en la que existen diversos actores implicados, principalmente, la Autoridad, los contratistas y los Estados patrocinadores. Tampoco existe un único enfoque relativo a la noción de daños ambientales en el derecho internacional del medio ambiente ${ }^{128}$. El régimen jurídico sobre responsabilidad previsto en la Convención, incluida la Parte XI, se basa en el principio de reparación del daño ambiental. Así lo establece el artículo 235 (2) al señalar que

125 Regla 31 (6), Reglamento sobre nódulos polimetálicos; Regla 33 (6), Reglamento sobre sulfuros polimetálicos; Regla 33 (6), Reglamento sobre costras de ferromanganeso.

${ }^{126}$ Recomendación C.38 (o).

127 ISBA/17/LTC/7, párr. 12.

128 Véase sobre el tema R. Mackenzie, "Liability for Environmental Harm from Deep Seabed Mining Activities: Defining Environmental Damage", Liability Issues for Deep Seabed Mining Series. Paper No. 8 - February 2019. 
"Los Estados asegurarán que sus sistemas jurídicos ofrezcan recursos que permitan la pronta y adecuada indemnización u otra reparación de los daños causados por la contaminación del medio marino por personas naturales o jurídicas bajo su jurisdicción".

Esta obligación de reparar está en consonancia con las normas de responsabilidad internacional de los Estados ${ }^{129}$ y con el Principio 13 de la Declaración de $\mathrm{Rio}^{130}$. El artículo 22 del Anexo III, relativo a la responsabilidad del contratista y de la Autoridad en relación con las actividades en la Zona, se refiere a la cuestión de la reparación indicando expresamente que, en todo caso, la reparación equivaldrá al daño efectivo.

\section{i) Responsabilidad de los Estados patrocinadores}

La Sala de Controversias ha entendido en su opinión consultiva que el alcance de la responsabilidad del Estado patrocinador depende de la naturaleza de la obligación violada ${ }^{131}$. Los Estados patrocinadores son responsables del incumplimiento de sus obligaciones directas, que se rige exclusivamente por la primera frase del artículo 139, según la cual, "los daños causados por el incumplimiento por un Estado Parte de sus obligaciones entrañarán responsabilidad". Por tanto, la responsabilidad del Estado patrocinador exige, además del incumplimiento de sus obligaciones, la producción de daños. En consecuencia, el Estado patrocinador no será responsable si ha incumplido sus

129 Art. 36, Proyecto de artículos sobre la responsabilidad del Estado por hechos internacionalmente ilícitos, Resolución 56/83 de la Asamblea General de las Naciones Unidas, de 12 de diciembre de 2001, Anexo.

130 "Los Estados deberán desarrollar la legislación nacional relativa a la responsabilidad y la indemnización respecto de las víctimas de la contaminación y otros daños ambientales. Los Estados deberán cooperar asimismo de manera expedita y más decidida en la elaboración de nuevas leyes internacionales sobre responsabilidad e indemnización por los efectos adversos de los daños ambientales causados por las actividades realizadas dentro de su jurisdicción, o bajo su control, en zonas situadas fuera de su jurisdicción".

131 Sobre opinión consultiva véase M. T. Ponte Iglesias, "La prospección y explotación de la zona internacional de los fondos marinos y oceánicos de una manera ambientalmente responsable: aportes de la primera opinión consultiva de la Sala de Controversias de Fondos Marinos", en J. J. Urbina (coord.), Protección de intereses colectivos en el derecho del mar y cooperación internacional, lustel, 2012, pp. 63-108; E. Salamanca Aguado, "La contribución de la opinión consultiva de la sala de controversias de fondos marinos del Tribunal Internacional del Derecho del Mar a la interpretación y aplicación de la parte XI de la convención de Naciones Unidas sobre el derecho del mar de 1982 y su acuerdo de 1994", en J. M. Sobrido Heredia (dir.), La contribución de la Convención de las Naciones Unidas sobre el Derecho del Mar a la buena gobernanza de los mares y océanos, Editoriale Scientifica, Vol. 1, 2014, pp. 385-406; T. Scovazzi, "The Exploitation of Resources of the Deep Seabed and the Protection of the Environment", German Yearbook of International Law, vol. 57, 2014, pp. 181- 207. 
obligaciones pero no se han producido daños, o si habiéndose producido daños, hubiese cumplido con sus obligaciones ${ }^{132}$. Esta condición constituye una excepción a la norma de derecho internacional general según la cual no se exige la producción de daños materiales para que un Estado sea responsable por el incumplimiento de sus obligaciones internacionales ${ }^{133}$.

La Sala distingue entre los daños producidos al PCH — la Zona y sus recursos - y el daño al medio marino. Los legitimados para reclamar como directamente lesionados serían la Autoridad en nombre de la humanidad, las entidades dedicadas a la minería de los fondos marinos, otros usuarios del mar y los Estados ribereños ${ }^{134}$. La Sala aplica además el párrafo 1 del artículo 48 del Proyecto de artículos de la CDI y considera que la obligación de preservar el medio marino en el Alta mar y en la Zona es una obligación erga omnes y en consecuencia cualquier Estado Parte estaría legitimado para reclamar por los daños causados ${ }^{135}$. Por último, se exige una relación de causalidad entre el incumplimiento de sus obligaciones directas y el daño causado, expresamente exigido por la primera frase del artículo $139(2)^{136}$. Esta relación de causalidad no puede presumirse, debe ser probada ${ }^{137}$.

Conviene recordar que la responsabilidad del Estado patrocinador por el incumplimiento de sus obligaciones en relación a los daños causados por un contratista patrocinado, se rige además por la segunda frase del artículo 139, en el que se dispone que

"el Estado Parte no será responsable de los daños causados en caso de incumplimiento de sus obligaciones por una persona a la que haya patrocinado, si ha tomado todas las medidas necesarias y apropiadas para lograr su cumplimiento efectivo".

Por tanto, el Estado patrocinador está exento de responsabilidad si ha adoptado dichas medidas, es decir, si ha cumplido con su obligación de

\footnotetext{
${ }^{132}$ Advisory Opinion, párr. 178.

${ }^{133}$ Véase el artículo 2 del Proyecto de artículos... cit.

${ }^{134}$ Advisory Opinion, párr. 179.

135 Ibíd., párr. 180.

136 Ibíd., párr. 181.

137 Ibíd., párr. 182.
} 
diligencia debida ${ }^{138}$. Por último, en aquellas situaciones en las que el Estado patrocinador no hubiese cumplido con sus obligaciones internacionales pero no se hubiesen producido daños al patrimonio común o al medio marino, o no fuese posible probar la relación de causalidad entre el daño y el incumplimiento, las consecuencias jurídicas de ese comportamiento ilegal quedarían determinadas por el derecho internacional general ${ }^{139}$.

\section{ii) Responsabilidad de los contratistas y de la Autoridad}

El artículo 22 del Anexo III regula la responsabilidad del contratista y de la Autoridad por los daños causados por los actos ilícitos cometidos en la realización de sus operaciones, o en el ejercicio de sus facultades y funciones, respectivamente. De este artículo se deduce que la responsabilidad principal derivada de la comisión de un ilícito cometido en la realización de operaciones del contratista o en el ejercicio de las facultades y funciones de la Autoridad recae en el contratista y la Autoridad, respectivamente, en lugar de en el Estado patrocinador ${ }^{140}$. En este contexto, la Sala de controversias ha considerado en su opinión consultiva que la responsabilidad del Estado patrocinador y la del contratista patrocinado existen paralelamente y no son solidarias. Sólo existe un punto de conexión: que la responsabilidad del Estado patrocinador se activa con los daños ocasionados por las acciones u omisiones del contratista patrocinado (trigger mechanism), pero los daños producidos por las actividades del contratista no son atribuibles directamente al Estado patrocinador. Consecuentemente, el Estado patrocinador no es responsable de los daños causados por el contratista patrocinado, no existe responsabilidad residual del Estado patrocinador ${ }^{141}$.

iii) Necesidad de un fondo de garantía ambiental

Del régimen de responsabilidad por daños descrito se desprende que hay determinadas situaciones que no están previstas, es decir, existen gaps in

\footnotetext{
138 Ibíd., párr. 177.

139 Ibíd., párr. 205.

140 Ibíd., párr. 200.

141 Ibíd., párr. 201.
} 
liability. En efecto, es posible que el Estado patrocinador haya tomado todas las medidas necesarias y apropiadas, es decir, haya cumplido con su obligación de diligencia debida, y el contratista patrocinado haya causado daños pero no puede cumplir totalmente con su responsabilidad. También puede producirse un gap -una laguna- si el Estado patrocinador no cumple con sus obligaciones, pero no puede probarse una relación de causalidad entre el incumplimiento y el daño producido. Como se ha indicado de conformidad con el artículo 139 no existe responsabilidad residual atribuible al Estado patrocinador; aunque la responsabilidad del Estado patrocinador depende de la producción de daños resultante de las operaciones del contratista, esto no hace al Estado patrocinador responsable del daño causado ${ }^{142}$. En estos supuestos la Sala de Controversias ha sugerido a la Autoridad el establecimiento de un fondo fiduciario para compensar el daño no cubierto por el contratista, según se prevé en el artículo $235(3)^{143}$.

\section{d) Principio de transparencia}

El principio de transparencia en la toma de decisiones está relacionado con el principio de participación pública en el derecho internacional del medio ambiente $^{144}$. El Principio 10 de la Declaración de Río se refiere a que "el mejor modo de tratar las cuestiones ambientales es con la participación de todos los ciudadanos interesados, en el nivel que corresponda". La transparencia es además un elemento esencial de la buena gobernanza y constituye un principio rector del plan estratégico de la Autoridad ${ }^{145}$. El compromiso con la transparencia se concreta en medidas destinadas a asegurar una participación mayor, más activa y más informada de los miembros de la Autoridad y otras partes interesadas mediante la adopción de métodos de trabajo precisos, selectivos y eficaces adoptando un enfoque inclusivo para la adopción de

142 Ibíd., párrs. 182 y 204.

143 Ibíd., párrs., 205 y 209. Sobre la cuestión de los fondos de indemnización ambiental en la práctica internacional véase Guifang, X., "The Use of the Compensation Funds, Insurance and Other Financial Security in Environmental Liability Schemes", Liability Issues for Deep Seabed Mining Series, Paper No. 6 - February 2019.

${ }^{144}$ Véase J. Ebbenson, "Public Participation", en D. Bodansky/J. Brunnée/E. Hey, The Oxford Handbook of International Environmental Law, Oxford University Press, 2010, pp. 681-703.

${ }_{145}$ Plan estratégico, Principio 4 (j). Véase J. A. Ardron (et al), "Incorporating transparency into the governance of deep-seabed mining in the Area beyond national jurisdiction", Marine Policy, 89 (2018) pp. 58-66. 
decisiones ${ }^{146}$. Asimismo, están destinadas a comunicar la información de su labor de manera oportuna y eficaz en función de los costos; garantizar el acceso a la información no confidencial; adoptar prácticas y procedimientos de trabajo claros, abiertos y eficaces en función de los costos y velar por que se comprenda plenamente y se gestione de manera adecuada la cadena de responsabilidad y rendición de cuentas de todos los agentes pertinentes para el desarrollo, la aplicación y el cumplimiento de reglamentos y estándares técnicos, ambientales, operacionales, científicos y de seguridad para las actividades en la Zona; y crear una estrategia y una plataforma de comunicación y consulta de las partes interesadas que facilite el diálogo abierto, fructífero y constructivo, en particular sobre las expectativas de las partes interesadas ${ }^{147}$.

El principio de transparencia es además un principio rector de los planes regionales de gestión ambiental. En concreto, la Autoridad se ha comprometido a permitir la participación del público en los procedimientos de adopción de decisiones ambientales de conformidad con la Convención sobre el acceso a la información, la participación del público en la toma de decisiones y el acceso a la justicia en asuntos ambientales, así como sus propias normas y procedimientos $^{148}$.

\section{Los planes regionales de gestión ambiental: requisito para el inicio} de las actividades de explotación de los minerales de la Zona

\section{a) Naturaleza jurídica y principios rectores}

En el contexto de los trabajos de la Autoridad encaminados a la aprobación del reglamento de explotación de los minerales de la Zona, que completará el "Código de Minería", existe consenso entre los Estados miembros a favor de la necesidad de establecer planes regionales de gestión ambiental (REMPs ${ }^{149}$ )

\footnotetext{
146 Orientación estratégica 8.2.

147 Orientaciones estratégicas 9.1, 9.2, 9.3, 9.4.

148 Plan regional de gestión ambiental para la zona Clarion - Clipperton, ISBA/17/LTC/7, 13 julio de 2011.

149 Sobre los REMPs (Regional Environmental Management Plans) véase "Regional Environmental Management Plans Are the Key to Deep-Sea Conservation", A fact sheet from
} 
para proteger eficazmente el medio marino de los efectos nocivos que puedan resultar de las actividades en la Zona en aplicación del criterio de precaución. Es decir, que se supedite la concesión de licencias de explotación a la existencia de dichos planes ${ }^{150}$. Las discrepancias surgen en torno a la naturaleza jurídica de los REMPs. La Secretaría ha explicado que si bien el fundamento de la decisión del Consejo de establecer los REMPs deriva de las facultades y funciones asignadas al Consejo en virtud de la Convención, esos planes no son de por sí instrumentos jurídicos, sino más bien instrumentos de política ambiental ${ }^{151}$. Sin embargo, algunas delegaciones, principalmente del grupo de Estados occidentales, consideran que sus disposiciones deben ser vinculantes y deberían aplicarse tanto mediante decisiones explícitas del Consejo en el momento de la adopción del plan como mediante la inclusión en el futuro reglamento sobre explotación de la obligación de que la declaración de impacto ambiental, el plan de gestión y vigilancia ambiental y el plan de cierre se ajusten al plan regional de gestión ambiental'52. Por tanto, el Consejo deberá considerar si se derivan obligaciones jurídicas de esos planes y, en caso afirmativo, la naturaleza y alcance de esas obligaciones en relación con los Estados Partes, los Estados patrocinadores y los contratistas.

Como ya hemos venido señalando, los REMPs se basan en un conjunto de principios rectores sobre los que se está diseñando toda la política ambiental de la Autoridad; a) el patrimonio común de la humanidad; b) el criterio de precaución; c) la protección y preservación del medio marino; d) la evaluación previa del impacto ambiental; e) la conservación y utilización sostenible de la diversidad biológica; f) la trasparencia. Sin embargo, no existe aún un modelo

Pew Charitable Trusts, July 2019, disponible en <https://www.pewtrusts.org//media/assets/2019/07/protecting-the-deep-sea v3.pdf> [Última visita: 29 de noviembre de 2019].

150 Véanse las declaraciones de los Estados miembros del Consejo durante la primera y segunda parte del $25^{\circ}$ período de sesiones del Consejo. Un resumen de los debates puede encontrarse en ENB Reports, disponibles en <https://enb.iisd.org/oceans/isa/2019-1/> y $<$ https://enb.iisd.org/oceans/isa/2019-2/> [Última visita: 15 de octubre de 2019].

151 Nota de la Secretaría. Relación entre el proyecto de reglamento sobre explotación de recursos minerales de la Zona y los planes regionales de gestión ambiental, ISBA/25/C/4, párr. 4.

152 Observaciones sobre el proyecto de reglamento sobre explotación de recursos minerales en la Zona presentado por la delegación de Alemania, ISBA/25/C/29, 27 de junio de 2019, párr. 12. Véase el proyecto de regulación 46 relativo al sistema de gestión ambiental que deberá aplicar el contratista, los proyectos de regulaciones 47 y 48 sobre la preparación de la declaración de impacto ambiental y el plan de gestión y vigilancia ambiental y el proyecto de Anexo VIII sobre el plan de cierre, ISBA/25/C/WP.1, 22 de marzo de 2019. 
único para la estandarización de los REMPs, cuestión que será objeto de debate en las próximas sesiones del Consejo ${ }^{153}$.

b) El plan regional de gestión ambiental para la Zona de fractura Clarion Clipperton

El Consejo aprobó en 2012 un plan de gestión ambiental para la Zona de Fractura Clarion - Clipperton ${ }^{154}$, elaborado por recomendación de la $\mathrm{CJT}^{155}$. Se trataba de una respuesta a la Resolución 63/11 de 12 de febrero de 2009 de la Asamblea General de las Naciones Unidas sobre los océanos y el derecho del mar. En ella la Asamblea General

"[r]eafirma la necesidad de que los Estados, a título individual o por conducto de las organizaciones internacionales competentes, examinen urgentemente los medios de integrar y perfeccionar, sobre la base de la mejor información científica disponible y el criterio de precaución, y con arreglo a la Convención y a los acuerdos e instrumentos conexos, el control de los riesgos para la biodiversidad de los montes marinos, los arrecifes de coral de aguas frías, los respiraderos hidrotérmicos y otros accidentes submarinos."

Y además,

"[e]xhorta a los Estados y a las organizaciones internacionales a que adopten con urgencia nuevas medidas para hacer frente, de conformidad con el derecho internacional, a las prácticas destructivas que tienen efectos adversos sobre la biodiversidad y los ecosistemas marinos,

\footnotetext{
153 Véanse, cuando estén disponibles, las conclusiones del International Expert Workshop: Towards a Standardised Approach to Regional Environmental Management Plans in the Area", organizado por Alemania, Holanda y Pew Charitable Trust, en Hamburgo, del 11 al 13 de noviembre de 2019. La información estará disponible en la página web de la Autoridad $<$ https://www.isa.org.jm/>.

${ }^{154}$ La zona Clarion - Clipperton se halla en la parte oriental del Pacífico central, al sur y sureste de las Islas Hawai. La zona limita al norte y al sur con las zonas de fractura Clarion - Clipperton de orientación este noreste y oeste noreste. El marino se encuentra en su mayor parte a una profundidad de entre 4.000 y 6.000 metros. En la actualidad han sido concedidas licencias de exploración a ocho contratistas con una superficie total aproximada de $520.000 \mathrm{~km}^{2}$ (téngase en cuenta que la superficie de España es de $505.990 \mathrm{~km}^{2}$ ). Su superficie total es aproximadamente $4,5 \times 10^{6} \mathrm{~km}^{2}$.

155 ISBA/18/C/22, 26 de julio de 2012 y ISBA/17/LTC/7, 13 de julio de 2011. Los datos y supuestos en que se basa el plan regional de gestión ambiental se derivan de un seminario dedicado a la delimitación de zonas marinas protegidas en los montes submarinos y la provincia de nódulos abisales de la alta mar del Océano Pacífico, realizado en la Universidad de Hawai en Manoa (EEUU) del 23 al 26 de octubre de 2007.
} 
incluidos los montes marinos, los respiraderos hidrotérmicos y los arrecifes de coral de aguas frías".

El REMP presenta tres tipos de objetivos. Los objetivos estratégicos que orientados a garantizar una explotación minera ambientalmente responsable. Los objetivos operacionales que comportan el establecimiento de bases de datos ambientales y evaluaciones del efecto ambiental acumulado. Y, por último, los objetivos de ordenación que establecen obligaciones para los contratistas en sus zonas de contrato ${ }^{156}$. Entre estas últimas se incluye la designación de la red de zonas de especial interés ambiental (APEls) excluidas de las actividades de exploración. Se trata de nueve zonas concebidas para mantener poblaciones sostenibles y albergar toda la diversidad de hábitats y comunidades, pues son suficientemente grandes como para mantener poblaciones mínimas viables de especies que podrían estar restringidas a una subregión de la Zona Clarion - Clipperton, sin verse afectadas por los penachos producidos por las actividades mineras adyacentes a una zona ${ }^{157}$. La CJT considera que al adoptar el REMP los criterios del Convenio sobre la Diversidad Biológica y la FAO, cuando se haya obtenido información suficiente sobre las APEls, se podrá promover su conversión en zonas marinas protegidas aceptadas en el plano internacional y situadas fuera de la jurisdicción nacional ${ }^{158}$.

\section{CONCLUSIONES}

Aún es pronto para aventurar una conclusión definitiva sobre el grado de eficacia de la política ambiental de la Autoridad a la hora de garantizar la protección del medio marino frente a los efectos derivados de las actividades

\footnotetext{
${ }^{156}$ Estas obligaciones consisten, principalmente, en la formulación de planes para velar por la gestión ambiental responsable a fin de reforzar la recuperación de los hábitats y las comunidades de fauna; la aplicación de los principios ISO 14001 en la formulación de sus planes de gestión ambiental para cada sitio; la indicación de la designación de ZRE y ZRP en sus planes de gestión ambiental con el propósito fundamental de asegurar la preservación y facilitar la vigilancia de las comunidades biológicas afectadas por actividades mineras; la inclusión en sus planes de gestión ambiental de medidas específicas que maximicen el potencial de recuperación de la biota afectada por sus actividades en la Zona Clarion Clipperton, ISBA/22/LTC/12, párr. 10.

157 ISBA/17/LTC/7, párr. 42.

158 ISBA/22/LTC/12, párr. 11.
} 
en la Zona. El grado de incertidumbre científica, técnica y económica es elevado y los desafíos son evidentes. Pero sí pueden esbozarse algunas conclusiones preliminares en cuanto a la estrategia seguida por la Autoridad a la hora de definir su política ambiental. Se puede valorar positivamente el esfuerzo por favorecer la participación de todos los agentes interesados en los procesos de tomas de decisiones, especialmente las organizaciones ecologistas que participan en las sesiones del Consejo y de la Asamblea y en los seminarios científicos que se organizan entre períodos de sesiones. También merece una opinión favorable el enfoque evolutivo y flexible (adaptive management) que conlleva la revisión y adaptación de sus reglamentos y directrices a los nuevos conocimientos científicos y a las nuevas tecnologías que buscan minimizar el impacto ambiental.

Existe además consenso entre los Estados miembros a favor de que no se inicie la fase de explotación hasta que no se hayan aprobado normas y directrices ambientales claras y eficaces, en aplicación del criterio de precaución. La Autoridad se ha esforzado por aplicar los principios del derecho internacional del medio ambiente e incluso ha innovado en la introducción de nuevos enfoques ambientales. Aún así, las críticas persisten, sobre la falta de transparencia, la falta de medidas apropiadas, el débil control ante los casos de incumplimientos por parte de algunos contratistas, las carencias institucionales por la falta de expertos etc... Tendremos que esperar a que finalice el proceso de elaboración del reglamento de explotación, incluidas las reglas y directrices ambientales, así como, los mecanismos de inspección que se están diseñando para poder concluir si la Autoridad ha cumplido o no con su misión de equilibrar la explotación y la conservación del patrimonio común. $Y$ más tiempo aún, cuando comience la comercialización de los minerales de la Zona, para valorar si la explotación se ha realizado en beneficio de la humanidad, y no sólo en términos económicos, sino también desde la perspectiva de la participación de los Estados en desarrollo en las actividades de explotación a través de la Empresa. Lo que es innegable a estas alturas es que el principio de patrimonio común de la humanidad ha resultado ser un principio operativo cuyo desarrollo y aplicación es ya una realidad. 


\section{BIBLIOGRAFIA}

Ardron, J. A., (et al), "Incorporating transparency into the governance of deepseabed mining in the Area beyond national jurisdiction", Marine Policy, 89 (2018) pp. 58-66.

Brunnée, J., "Common Areas, Common Heritage and Common Concern”, en D. Bodansky (et al), The Oxford Handbook of International Environmental Law, Oxford University Press, 2010, pp. 550 - 553.

Durden, J. M. (et al), "Environmental Impact Assessment process for deep-sea mining in the Area", Marine Policy, 87 (2018) pp. 194-202.

Ebbenson, J., "Public Participation", en D. Bodansky/J. Brunnée/E. Hey, The Oxford Handbook of International Environmental Law, Oxford University Press, 2010, pp. 681-703.

Guifang, X., "The Use of the Compensation Funds, Insurance and Other Financial Security in Environmental Liability Schemes", Liability Issues for Deep Seabed Mining Series, Paper No. 6 - February 2019.

Hardi, G., "The Tragedy of the Commons", Science, vol. 162, p. 1244.

Jaeckel, A., "An Environmental Management Strategy for the International Seabed Authority? The Legal Basis, The International Journal of Marine and Coastal Law, 30 (2015) pp. 93 - 119.

Ponte Iglesias, M. T., "La prospección y explotación de la zona internacional de los fondos marinos y oceánicos de una manera ambientalmente responsable: aportes de la primera opinión consultiva de la Sala de Controversias de Fondos Marinos", en J. J. Urbina (coord.), Protección de intereses colectivos en el derecho del mar y cooperación internacional, lustel, 2012, pp. 63-108.

Salamanca Aguado, E., La Zona internacional de los fondos marinos. Patrimonio Común de la Humanidad, Dykinson, 2003. 
Salamanca Aguado, E., "La contribución de la opinión consultiva de la sala de controversias de fondos marinos del Tribunal Internacional del Derecho del Mar a la interpretación y aplicación de la parte XI de la Convención de Naciones Unidas sobre el Derecho del Mar de 1982 y su Acuerdo de 1994", en J. M. Sobrino Heredia (dir.), La contribución de la Convención de las Naciones Unidas sobre el Derecho del Mar a la buena gobernanza de los mares y océanos, Editoriale Scientifica, Vol. 1, 2014, pp. 385-406.

Salamanca Aguado, E., "El régimen jurídico aplicable a la bioprospección de los recursos genéticos de los fondos oceánicos fuera de los límites de la jurisdicción nacional”, R.E.D.I., vol. LVIII (2006), 2, pp. 1072 - 1078.

P. Sands/J. Peel, Principles of International Environmental Law, Cambridge University Press, 2018.

Scovazzi, T., "The Exploitation of Resources of the Deep Seabed and the Protection of the Environment", German Yearbook of International Law, vol. 57, 2014, pp. 181- 207.

Shama, R., "Environmental Issues of Deep-Sea Mining", Procedia Earth and Planetary Science 11 (2015) pp. $204-211$.

Simon-Lledó, E., "Biological effects 26 years after simulated deep-sea mining", Scientific Reports (2019) 9:8040.

Van Dover, C. L., (et al), "Scientific rationale and international obligations for protection of active hydrothermal vent ecosystems from deep sea mining", Marine Policy, 90 (2018) pp. 20-28.

Vázquez Gómez, E. M., "La protección de la biodiversidad biológica más allá de la jurisdicción nacional. Hacia un nuevo acuerdo de aplicación de la Convención de Naciones Unidas sobre el Derecho del Mar", R.E.E.I., Número 37 , junio 2019.

Washburn, T. W. (et al), "Ecological risk assessment for deep-sea mining", Ocean and Coastal Management 176 (2019) pp. 24-39. 